\title{
Abnormal Crosstalk between Endothelial Cells and Podocytes Mediates Tyrosine Kinase Inhibitor (TKI)-Induced Nephrotoxicity
}

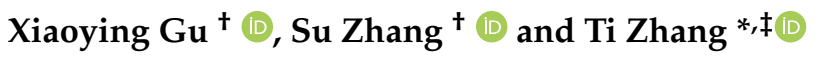 \\ Department of Hepatobiliary Surgery, Tianjin Medical University Cancer Institute \& Hospital, National Clinical \\ Research Center for Cancer, Tianjin's Clinical Research Center for Cancer, Key Laboratory of Cancer Prevention \\ and Therapy, Tianjin 300060, China; guxiaoying@tmu.edu.cn (X.G.); zhangsu@tmu.edu.cn (S.Z.) \\ * Correspondence: zhangti@shca.org.cn; Tel.: +86-21-6417-5590 \\ + These authors contributed equally to this work. \\ ‡ Present address: Department of Hepatic Surgery, Fudan University Shanghai Cancer Center, \\ Shanghai Medical College, Fudan University, Shanghai 200032, China.
}

check for updates

Citation: Gu, X.; Zhang, S.; Zhang, T. Abnormal Crosstalk between Endothelial Cells and Podocytes Mediates Tyrosine Kinase Inhibitor (TKI)-Induced Nephrotoxicity. Cells 2021, 10, 869. https://doi.org/ 10.3390/cells10040869

Academic Editors: Alexander E. Kalyuzhny and Guo-Chang Fan

Received: 28 February 2021

Accepted: 9 April 2021

Published: 12 April 2021

Publisher's Note: MDPI stays neutral with regard to jurisdictional claims in published maps and institutional affiliations.

Copyright: (c) 2021 by the authors. Licensee MDPI, Basel, Switzerland. This article is an open access article distributed under the terms and conditions of the Creative Commons Attribution (CC BY) license (https:// creativecommons.org/licenses/by/ $4.0 /)$.

\begin{abstract}
Vascular endothelial growth factor A (VEGFA) and its receptor VEGFR2 are the main targets of antiangiogenic therapies, and proteinuria is one of the common adverse events associated with the inhibition of the VEGFA/VEGFR2 pathway. The proteinuric kidney damage induced by VEGFR2 tyrosine kinase inhibitors (TKIs) is characterized by podocyte foot process effacement. TKI therapy promotes the formation of abnormal endothelial-podocyte crosstalk, which plays a key role in TKI-induced podocyte injury and proteinuric nephropathy. This review article summarizes the underlying mechanism by which the abnormal endothelial-podocyte crosstalk mediates podocyte injury and discusses the possible molecules and signal pathways involved in abnormal endothelialpodocyte crosstalk. What is more, we highlight the molecules involved in podocyte injury and determine the essential roles of Rac1 and Cdc42; this provides evidence for exploring the abnormal endothelial-podocyte crosstalk in TKI-induced nephrotoxicity.
\end{abstract}

Keywords: angiogenesis; tyrosine kinase inhibitors; nephrotoxicity; endothelial cells; podocytes; crosstalk; Rac1; Cdc42

\section{Introduction}

Vascular endothelial growth factor A (VEGFA) and its receptor VEGFR2 are the main drivers of tumor angiogenesis and the main targets of antiangiogenic therapies [1]. VEGFAVEGFR2 inhibitors can be classified into two categories based on their targets: drugs that directly inhibit VEGFA, such as bevacizumab and VEGFA trap versus tyrosine kinase inhibitors (TKIs) that inhibit VEGFR2, such as sorafenib, lenvatinib, apatinib, regorafenib [2], etc. Inhibition of the VEGFA/VEGFR2 pathway has shown remarkable efficacy in improving the prognosis of patients with cancer. At the same time, these drugs also lead to some unignorable adverse events such as proteinuria, hypertension, hand-foot syndrome, etc. Among these adverse events, proteinuria attracts attention for its high incidence, great impact on cancer treatment, and lack of effective interventions. In two phase II clinical trials published recently, the incidence of proteinuria in patients taking regorafenib and lenvatinib was 58\% [3] and 83\% [4], respectively. In patients taking lenvatinib, proteinuria was the most frequent adverse event contributing to dose reduction; it resulted in 52\% of participants experiencing dose reduction [4]. When the VEGFR2 monoclonal antibody ramucirumab was combined with other types of TKI, such as the EGFR inhibitor erlotinib, the incidence of proteinuria was significantly increased (ramucirumab vs. ramucirumab + erlotinib: $20 \%$ vs. $34 \%$ ), and proteinuria was the most common adverse event that led to ramucirumab dose reduction [5]. The administration of other VEGFA-VEGFR2 inhibitors also caused proteinuria (Table 1) [6-11]. A reduction in the dose of these agents inevitably affects their antitumor effect. Despite the fact that angiotensin II receptor blockade (ARB) effectively reduced proteinuria in various kidney diseases such as diabetic 
nephropathy, obesity-induced renal disease, and HIV-associated nephropathy [12-15], and that angiotensin-converting enzyme inhibitors (ACEIs) or ARB are recommended for alleviating proteinuria caused by diabetic nephropathy according to guidelines for treating diabetic nephropathy, in clinical practice, ARB did not effectively alleviate the proteinuria caused by bevacizumab; the patient had persistently elevated proteinuria while taking telmisartan [16]. The administration of ACEIs even compromised the anticancer efficacy of antiangiogenic drugs $[17,18]$. These facts make proteinuria an urgent problem, and the key to solving this problem is to thoroughly understand the mechanism of proteinuria induced by VEGFA-VEGFR2 inhibitors.

Table 1. The incidence of VEGF inhibitor-related proteinuria.

\begin{tabular}{|c|c|c|c|c|}
\hline Drug & Class & Targets & Proteinuria (\%) & References \\
\hline Lenvatinib & TKI & VEGFRs, FGFR1-4, RET, KIT, PDGFR $\alpha$ & 83 & {$[4,19]$} \\
\hline Regorafenib & TKI & VEGFRs, TIE2, KIT, RET & 58 & {$[3,19]$} \\
\hline Apatinib & TKI & VEGFR2 & 47.7 & {$[6,19]$} \\
\hline Cediranib & TKI & VEGFRs, PDGFR, KIT, & 37.8 & {$[7,20]$} \\
\hline Axitinib & TKI & VEGFRs, PDGFR, KIT & 29.0 & {$[8,21]$} \\
\hline Linifanib & TKI & VEGFRs, PDGFR & 27.3 & {$[7,22]$} \\
\hline Pazopanib & TKI & VEGFRs, PDGFR, KIT & 13.5 & {$[7,23]$} \\
\hline Sorafenib & TKI & VEGFRs, PDGFR $\beta$, RAF1, BRAF, KIT & 11.6 & {$[7,19]$} \\
\hline Sunitinib & TKI & VEGFRs, PDGFR, KIT, RET, CSF1R, FLT3 & 11.1 & {$[11,21]$} \\
\hline Vandetanib & TKI & VEGFR2-3, RET, EGFR & 10.0 & {$[7,21]$} \\
\hline Tivozanib & TKI & VEGFRs & 9.6 & {$[7,19]$} \\
\hline Ramucirumab & $\mathrm{mAb}$ against VEGFR2 & VEGFR2 & 20 & {$[10,19]$} \\
\hline Bevacizumab & mAb against VEGFA & VEGFA & $21-62$ & [9] \\
\hline
\end{tabular}

Under physiological conditions, except for mediating angiogenesis, the VEGFA/VEGFR2 pathway also plays an important role in the development and function maintenance of the kidneys [24]; the inhibition of different molecules on this pathway leads to different kidney pathological phenotypes. VEGFA inhibitors mainly resulted in renal thrombotic microangiopathy (TMA) with glomerular endothelial swelling and focal glomerular capillary thrombosis as the main pathological features [25], while renal biopsies from patients accepting TKI therapy showed minimal change nephropathy / focal segmental glomerulopathy (MCN/FSG)-like lesions, characterized by podocyte foot process effacement [26-28]. However, considering the small number of patients enrolled in these studies, this conclusion needs further verification. In addition to TKIs, there are various etiologies leading to proteinuric nephropathies characterized by $\mathrm{MCN} /$ focal segmental glomerulosclerosis (FSGS), such as diabetic nephropathy. Despite the similar pathological types, TKI-induced nephropathy is quite different from the others. For example, the expression levels of VEGFA and VEGFR2 were significantly increased in early diabetic nephropathy, the inhibition of the VEGFA/VEGFR2 pathway attenuated proteinuria [29], while in patients taking TKIs, the expression levels of VEGFA and VEGFR2 were lower than normal [17,28], which is the opposite of diabetic nephropathy. This indicated that, even with similar pathological changes, the mechanism may be totally different.

Proteinuria is closely related to the destruction of integrity of the glomerular filtration barrier, which is composed of podocytes, a glomerular basement membrane, and endothelial cells [30]. Highly differentiated, specialized podocytes are essential to maintain the integrity of the glomerular filtration barrier [30]. Podocytes have a complex structure consisting of three subcellular compartments: a cell body, microtubule-driven primary processes, and actin-driven foot processes [31]. Actin cytoskeletal remodeling 
results in podocyte foot process effacement, which is the main structural change leading to proteinuria [30,32]. In normotensive and hypertensive rats, VEGFR-2 kinase inhibition treatment resulted in podocyte foot process effacement [33], and the specific mechanism remains unclear. This review mainly focuses on TKI-induced proteinuric nephropathy and summarizes its possible underlying mechanisms.

\section{VEGFA/VEGFR2 Pathway and Proteinuria}

Podocyte injury is thought to be the initiating cause of proteinuric kidney diseases [34]. However, the comparison of kidney damage associated with TKIs and VEGFA inhibitors demonstrated that the former was characterized by high expression of c-maf-inducible protein (c-mip) in podocytes, while the latter was characterized by significantly increased expression levels of RelA (also called p65 NF- $\mathrm{KB}$ ) in podocytes and endothelial cells [28]. Under normal conditions, RelA was only expressed in podocytes and prevented the transcriptional activation of c-mip by binding to its promoter [28]. This indicated that the glomerulopathy associated with TKIs mainly affected podocytes, whereas anti-VEGFA therapy mainly affected endothelial cells and podocyte injury may be a secondary event [28]. Correspondingly, in a podocyte-specific VEGFA deletion experimental murine model, endothelial damage and proteinuria occurred prior to podocyte injury after eliminating VEGFA production from podocytes [25].

Coincidentally, in the process of transforming growth factor- $\beta$ (TGF- $\beta$ ) inducing FSGS, endothelial damage and proteinuria caused by the overexpression of podocytespecific TGF- $\beta$ occurred before podocyte injury [35]. This study demonstrated the role of abnormal crosstalk between endothelial cells and podocytes in kidney injury. Podocytespecific TGF- $\beta$ signaling promoted the release of endothelin-1 (EDN1) from podocytes, thereby activating EDN1 receptor type A (EDNRA) on the surface of endothelial cells, which mediated mitochondrial oxidative stress and the dysfunction of adjacent endothelial cells. Subsequently, endothelial dysfunction promoted proteinuria, podocyte apoptosis, glomerulosclerosis, and renal failure, which can be prevented by inhibiting EDNRA or scavenging mitochondrial-targeted ROS [35]. A similar sequence of cell damage suggests the existence of abnormal crosstalk between podocytes and endothelial cells after antiVEGFA treatment.

For patients treated with TKIs or VEGFA inhibitors, no one developed MCN/FSGlike lesions and TMA at the same time [28], but both lesions were observed in different patients receiving the same treatment regimen $[26,28]$. Our previous study achieved the same results: both TMA and FSG-like lesions were observed in an apatinib-induced proteinuria mouse model [17]. In normal kidneys, VEGFA is mainly produced by podocytes and binds to VEGFR2 on the surface of endothelial cells [36] to maintain the structure and function of the endothelium. TKIs and VEGFA inhibitors all function by blocking the VEGFA/VEGFR2 pathway; the related kidney injury is not only associated with endothelial damage, but also with podocyte injury. These findings further indicate that VEGFA-VEGFR2 inhibitors contribute to kidney injury by mediating the formation of abnormal crosstalk between podocytes and endothelial cells, rather than only interrupting the VEGFA/VEGFR2 signaling pathway.

\section{The Mechanism Underlying Abnormal Endothelial-Podocyte Crosstalk}

Although VEGFA-VEGFR2 inhibitors reduce the levels of VEGFA and VEGFR2 in the kidneys of patients with cancer [17,28], not all patients develop proteinuria. Despite the fact that VEGFA and VEGFR2 are the main drivers of angiogenesis, there are many other pro-angiogenic factors $[37,38]$, some of which have been found to be associated with kidney injury. For example, the overexpression of TGF- $\beta$ caused proteinuria [35], while the increased expression of angiopoietin-like factor 4 (Angptl4) reduced proteinuria by interacting with glomerular endothelial $\alpha \mathrm{v} \beta 5$ integrin [39].

These findings provide a possible explanation for the underlying mechanism by which VEGFA-VEGFR2 inhibitors mediate kidney injury and proteinuria through intercellular 
crosstalk: the administration of VEGFA-VEGFR2 inhibitors induces glomerular capillary endothelial damage by blocking the normal crosstalk mediated by VEGFA/VEGFR2 between podocytes and endothelial cells. In the early stage of TKI administration, the degree of endothelial dysfunction is mild and not enough to produce proteinuria. In patients without proteinuria, the damaged endothelial cells may promote the compensatory production of nephroprotective pro-angiogenic factors. On the contrary, in kidneys of patients with proteinuria, the abnormal endothelial-podocyte crosstalk can lead to podocyte injury through directly acting on podocytes or inducing the production of compensatory pro-angiogenic factors, which are harmful to podocytes. As kidney damage gradually worsens, endothelial cells can be affected. Upon the administration of VEGFA inhibitors, serious endothelial damage can directly lead to proteinuria and then cause podocyte injury through the same process as TKI administration. There are no studies on this hypothesis so far, which requires further exploration.

\section{Possible Endothelial-Podocyte Crosstalk in TKI-Induced Proteinuria}

Current studies on other kidney diseases elucidate several molecules and signal pathways mediating endothelial-podocyte crosstalk and participating in the development of proteinuric nephropathies. These molecules and related signaling pathways may be involved in the occurrence of TKI-induced proteinuric nephropathy.

\subsection{Neuropilin-1 (NRP1)}

In the regulation of VEGF signaling, NRP1 plays an important role in endothelial cells. NRP1 is a co-receptor of receptor tyrosine kinases that can enhance the activity of VEGFR2 by binding to VEGFR2 in a VEGFA-dependent manner and can increase the motility of endothelial cells [40]. The complex between NRP-1 and VEGFR2 can be formed between receptors present on different cells [40], making it possible for NRP-1 to mediate endothelial-podocyte crosstalk. In the glomeruli of diabetic nephropathy mice, the expression of the NRP-1 protein was reduced in podocytes, and the reversals of podocyte injury and proteinuria were associated with the restoration of NRP-1 expression [41]. The alteration of NRP1 expression in the kidneys during TKI therapy and whether NRP1 is involved in the development of podocyte injury and proteinuria mediated by TKIs remain unclear.

\subsection{Angiopoietin1 (ANGPT1)/TIE2 Pathway}

In the kidneys, ANGPT1 is mainly produced by podocytes and acts through the TIE2 expressed by endothelial cells. In the process of renal blood vessel development, this signaling pathway can promote blood vessel maturation [36]. In inflammation, ANGPT1 can stabilize vascular endothelial-cadherin (VE-cadherin) at the adherens junctions by activating Rac1, which enhances vascular barrier defense against inflammatory stimuli; additionally, it can reduce the infiltration of immune cells. All these contribute to maintaining the stabilization of the endothelium [42]. While in developed kidney, most research on ANGPT1/TIE2 has focused on its role in kidney disease. In the early stage of diabetic kidney disease, the expression of ANGPT1 in the kidneys was upregulated and returned to the control level or lower in the later stage [36]; podocyte-specific inducible repletion of ANGPT1 in early diabetic kidney disease reduced albuminuria [43], indicating a protective role of ANGPT1 for the kidneys, which may be attributed to the anti-inflammatory effect and the maintenance of vascular integrity mediated by ANGPT1. In tumor therapy, TIE2 is the target of some TKIs $[19,44]$. In brain tumors, VEGFR2 inhibition promoted vascular normalization through the upregulation of ANGPT1, enhancing the outcome of combined radiation therapy [45]. The combination of exogenous ANGPT1, TKIs, and other antitumor drugs may alleviate proteinuria while enhancing the antitumor effect. 


\subsection{Autocrine Epidermal Growth Factor (EGF)/EGF Receptor (EGFR)}

Previous studies have demonstrated the role of EGF/EGFR in various nephropathies. In rapidly progressive crescentic glomerulonephritis, the expression of heparin-binding EGF (HB-EGF) was found to be significantly elevated [46]. In vitro, podocytes from Hbegf $(-/-)$ glomeruli presented a migratory phenotype. The administration of EGFR-TKI or podocyte-specific EGF knockout prevented the increase in podocyte motility [46]. In Hbegf $(+/+)$ mice, the induction of nephrotoxic serum (NTS) resulted in mild to severe podocyte foot process effacement, while the administration of EGFR-TKI or podocyte-specific EGF knockout improved proteinuria, podocyte injury, kidney damage and decreased renal function [46]. In podocytes of diabetic nephropathy, downregulated Gprc5a mediates podocyte foot process effacement, FSGS, and proteinuria by upregulating EGFR and TGF- $\beta$ signaling pathways [47]; an upregulated EGFR signal can also promote the activation of the TGF- $\beta$ signaling pathway [48]. Additionally, EGFR can be transactivated. Agonists such as angiotensin II, endothelin, IL-8, ROS, TGF- $\beta 1$, combined with G-protein coupled receptors to activate intracellular kinases such as Src and PKC, subsequently cleaved EGFR ligands through phosphorylating A disintegrin and metalloproteinase (ADAM) family members $[36,49]$. The transactivation of EGFR increases the possibility of EGF/EGFR being involved in the nephropathy related to TKIs, since the metabolites of the damaged endothelial cells may lead to podocyte injury through this way. However, although EGFR-TKI alleviated proteinuria and kidney injury in crescentic glomerulonephritis [46], in clinical trials, the combination of VEGFR2 monoclonal antibody ramucirumab and EGFR inhibitor erlotinib resulted in the increased incidence of proteinuria compared to ramucirumab alone [5]. Therefore, we should be cautious in using EGFR-TKI to alleviate the proteinuria induced by VEGFR2 inhibition, and further research is required to clarify the change in the EGF/EGFR signaling pathway during TKI therapy.

\subsection{Semaphorin $3 A$ (Sema3A)}

Sema3A is mainly produced by mature podocytes and is thought to be involved in endothelial-podocyte crosstalk in diabetic nephropathy [29]. Previous studies reported that this molecule seems to mediate podocyte injury and proteinuria through the downregulation of VEGFA/VEGFR2 signaling [29,36]. After the injection of exogenous Sema3A, the kidney showed podocyte foot process effacement and endothelial damage, accompanied by the decreased expression of VEGFR2 and the downregulation of podocin, nephrin, and CD2-related proteins (CD2-AP), all of which were prevented by the co-administration of VEGF165 and Sema3A [50]. This demonstrated that the change in the expression of Sema3A may not be the reason for VEGFA-VEGFR2 inhibitor-related proteinuria; it is more likely a susceptibility factor-that is, patients having a higher level of Sema3A at the onset of taking VEGFA-VEGFR2 inhibitors may be prone to developing proteinuria. However, the role of Sema3A in tumors is complex. In mouse models of pancreatic neuroendocrine tumors and cervical carcinoma, the expression of Sema3A overcomes proinvasive and prometastatic resistance [51], while the knockdown of Sema3A increased the sensitivity of Lewis lung cancer cells to EGFR-TKIs gefitinib and erlotinib [52]. Therefore, alleviating TKI-induced proteinuria without affecting the anticancer effect of TKIs through targeting Sema3A is a huge challenge.

\subsection{CXCL12/CXCR4}

Chemokine CXCL12 (SDF-1) and its receptor CXCR4 are expressed by podocytes and endothelial cells, respectively [36]. This system is vital to glomerular vascular development. CXCL12- and CXCR4-deficient kidneys had identical abnormal blood vessel development that featured the ballooning of the developing glomerular tuft and disorganization of the renal vasculature [53]. In the process of neo-angiogenesis, CXCL12 plays an essential role in the recruitment of CXCR4 (+) pro-angiogenic bone marrow (BM) cells, including subsets of hematopoietic cells and endothelial progenitor cells [54], and this system can work synergistically with the VEGF system, the latter subsequently promoting arterial 
differentiation [55]. However, the function of CXCL12/CXCR4 in podocyte injury and kidney diseases is controversial. The inhibition of CXCL12 in mice with diabetic nephropathy alleviated glomerulosclerosis, prevented proteinuria, and podocyte loss [56], but in another study, dipeptidyl peptidase-4 (DPP-4) inhibition suppressed the progression of diabetic nephropathy by upregulating CXCL12, indicating a protective effect of CXCL12 on podocytes and kidneys [57]. In VEGFR-expressing glioblastoma, it has been confirmed that VEGFR inhibitors upregulated CXCR4 through TGF- $\beta$ /TGF- $\beta$ receptor [58], and the inhibition of CXCR4 enhanced the efficacy of sunitinib (a multitarget TKI) in preclinical models of human glioblastoma [59]. In TKI-induced proteinuric kidney disease, the expression of the CXCL12/CXCR4 system may be altered to participate in the abnormal endothelial-podocyte crosstalk or to protect podocytes and maintain the integrity of the vascular system. More investigations are required to determine the specific role of the CXCL12/CXCR4 system in TKI-induced proteinuria.

\subsection{WT1}

WT1 is a podocyte-specific transcription factor that can promote normal crosstalk between podocytes and endothelial cells by modulating the bioavailability of VEGFA. In normal kidneys, WT1 promoted the expression of 6-O-endosulfatases (Sulf) to reduce the 6-O-sulfation of heparan sulfate chains within heparan sulfate proteoglycans (HSPGs) on the surface of podocytes, inhibiting the binding of HSPGs and VEGFA, and increased the release of VEGFA by podocytes [60]. WT1 can also directly upregulate the expression of VEGFA [61]. In the podocytes of FSGS, elevated expression of microRNA-193a reduced WT1 expression and thereby downregulated target genes of WT1 that are vital to podocyte structure, including PODXL (podocalyxin), NPHS1 (nephrin), VEGFA (VEGFA), etc., eventually leading to kidney disease and proteinuria [61]. Based on these results, the kidneys of patients with lower WT1 expression at the onset of administration of VEGFA-VEGFR2 inhibitors may be more vulnerable to these agents.

\subsection{Endothelial Thrombomodulin-Protein C}

Recent studies have found that the coagulation system participates in the development of kidney disease through its non-hemostatic function. Endothelial-podocyte crosstalk mediated by the thrombomodulin-protein C system was found in diabetic nephropathy [62]. Thrombomodulin expressed in glomerular endothelial cells activated endothelial protein $\mathrm{C}$ by binding to thrombin, and then activated protein $\mathrm{C}(\mathrm{aPC})$ promoted the dimerization of PAR3 and PAR2 in human podocytes and that of PAR3 and PAR1 in murine podocytes through activating PAR3, which subsequently limited the production of mitochondrial ROS by suppressing the redox enzyme p66Shc [62]. This crosstalk between endothelial cells and podocytes can protect podocytes from injury, which has been confirmed by the improvement of diabetic nephropathy in mice through exogenous administration of aPC [63]. Inflammation or cell dysfunction can reduce the expression of thrombomodulin and destroy this protective crosstalk [62]. Currently, protective effects of aPC on endothelial cells and podocytes, as well as the improvement of vascular damage, were found in the case of high VEGF expression [63-65]. Further verification is needed to explore the possibility that the damage of endothelial cells mediates podocyte injury and proteinuria through the destruction of the thrombomodulin-aPC pathway in the early stage of TKI therapy.

\subsection{Integrin-Linked Kinase (ILK)}

ILK is a serine threonine kinase that can interact with the cytoplasmic domain of $\beta$-integrin, playing a key role in regulating integrin-mediated podocyte-matrix adhesion $[66,67]$. Under physiological conditions, the complex formed by ILK, nephrin, and $\alpha$-actinin- 4 maintains the normal foot process structure of the podocytes and the integrity of the slit diaphragm. The podocyte-specific ablation of ILK destructed this complex, leading to severe proteinuria, glomerulosclerosis, and renal failure [68]. In podocyte injury and proteinuria caused by various injury stimuli, ILK expression was increased in podocytes. 
The blockade of ILK activity maintained the normal shape and function of podocytes [69]. ILK is the target gene of TGF- $\beta$ /Smad signaling [66]. TGF- $\beta$ has been confirmed to play a central role in the phenotypic transition of renal tubular epithelial cells and podocytes after injury [66]. In response to hypoxia or oxidative stress, renal tubular epithelial cells mediate the infiltration of inflammatory cells by producing various chemokines and cytokines. The mixture of pro-inflammatory cytokines produced by these inflammatory cells can enhance TGF- $\beta$ signaling by inducing the expression of TGF- $\beta$ receptors, and TGF- $\beta$ can be produced by injured tubular epithelial cells or inflammatory cells [66]. TKI therapy can induce oxidative stress [70-72] and has been confirmed to induce upregulated TGF- $\beta[73,74]$, which may mediate podocyte damage in a way similar to that of the tubular epithelial cell injury induced by TGF- $\beta$. Additionally, ILK may also be associated with TKIs through c-mip. In membranous nephropathy, the upregulation of c-mip was closely related to podocyte dysfunction, as well as the downregulation of synaptopodin and upregulation of ILK [75]. Additionally, sorafenib has been proven to induce the high expression of c-mip in podocytes [28]. However, the changes in ILK in kidneys treated with TKIs have not yet been reported yet. In tumor cells, the high expression of ILK can promote tumor angiogenesis and tumor progression by inducing VEGF expression [76-78]. Highly expressed ILK was an independent poor prognostic factor for progression-free survival in patients with non-small-cell lung cancer (NSCLC) [79], while the knockdown of ILK gene made lung squamous cell carcinoma sensitive to TKI therapy [80]. In prostate cancer, the anticancer effect of TKI therapy was related to the reduced expression of ILK [81]. Together, these factors demonstrate that ILK may be a potential target to simultaneously reduce proteinuria and enhance the anticancer efficacy of TKIs.

\subsection{Oxidative Stress}

In the human body, the oxygen consumption and mitochondrial enrichment of the kidney is second only to the heart [82]. Studies have emphasized the involvement of mitochondria in the process of chronic kidney injury $[83,84]$, which is mainly due to the reduction in mitochondrial DNA replication, loss of mitochondrial membrane potential, and decreased ATP production [85]. In chronic kidney disease, the progressive deterioration of renal function can induce some biological dysfunction, including changes in cellular energy metabolism, protein malnutrition, and the synthesis of a large number of oxidative stress mediators $[86,87]$. Some studies have reported that, even in the very early stages of chronic kidney disease, there is a large amount of reactive oxygen generated and upregulation of oxidative stress markers, such as lipid peroxide (MDA). The levels of all these oxidative stress markers are negatively correlated with the glomerular filtration rate [88-91]. As mentioned above, the mitochondrial dysfunction induced by EDN1/EDN1 receptor in glomerular endothelial cells can lead to podocyte loss, proteinuria, and glomerular sclerosis, which can be prevented by inhibiting EDN1 receptor or mitochondrial-mediated oxidative stress [35]. The same results were verified in animal models of diabetic nephropathy, suggesting the existence of crosstalk between glomerular endothelial injury and podocytes [92]. In the development of proteinuria induced by sunitinib, the EDN1/EDN1 receptor pathway and oxidative stress have been confirmed to play important roles [71]. These factors indicate the possibility that TKIs may induce podocyte injury and proteinuria through the abnormal endothelial-podocyte crosstalk mediated by oxidative stress.

Taken together, these molecules and related pathways have the ability to participate in the abnormal endothelial-podocyte crosstalk mediating TKI-induced proteinuric kidney disease, but their specific role needs further exploration.

\section{Cell Motility-Related Molecules: Rac1 and Cdc42}

According to the conjecture above, podocyte injury is the key to TKI-induced nephropathy, and endothelial damage is the initial factor. Podocyte injury can, therefore, be taken as the entry point to find the compensatory pro-angiogenic factors. In the process of angiogenesis, vascular barrier repair, and podocyte foot process effacement, both endothelial 
cells [93] and podocytes [94] show increased motility. This similarity provides evidence for finding the compensatory pro-angiogenic factors that participate in abnormal endothelialpodocyte crosstalk in the proteinuric nephropathy associated with TKIs.

Endothelial cell migration is a key step of angiogenesis mediated by pro-angiogenic factors [93]; blocking this step significantly inhibits angiogenesis [95,96]. The actin cytoskeleton plays a crucial role in endothelial cell migration through continuous remodeling into filopodia, lamellipodia, and stress fibers [93]. The formation of filopodia is mainly regulated by the activation of Rho GTPase family member Cdc42, and the formation of lamellipodia is closely related to actin polymerization involving Rac1, another member of the Rho family GTPases [93].

In podocyte damage and proteinuria, cytoskeletal regulation also plays an important role. The summarization of molecules involved in the regulation of the podocyte actin cytoskeleton and their signaling pathways indicates that Rac1 and Cdc42 may be the key intersections mediating angiogenesis and podocyte injury induced by the compensatory pro-angiogenic factors mentioned above.

\subsection{The Role of Rac1 and Cdc42 in Podocyte Injury}

The Rho GTPase family members involved in podocyte foot process effacement and proteinuric nephropathies include RhoA, Cdc42, and Rac1. The activation of RhoA mediates the formation of stress fibers in podocytes and the maintenance of the integrity of podocyte actin cytoskeleton [97], keeping podocytes in a healthy stationary phenotype [94]; on the contrary, the activation of Cdc42 and Rac1 leads to podocyte injury and proteinuria [98-100].

The mutual antagonism between RhoA, Rac1, and Cdc42 depends on RhoA inhibiting the activities of Rac1 and Cdc42. The activities of Rho family GTPases are regulated by guanine nucleotide exchange factors (GEFs), GTPase-activating proteins (GAPs), and GDP dissociation inhibitors (GDIs), among which the GEFs activate Rho GTPases from an inactive GDP-bound state to an active GTP-bound state, whereas GAPs inactivate Rho GTPases and GDIs inhibit Rho GTPases activities (Figure 1) [94]. RhoA can activate Arhgap24 protein (GAP) through its effector kinase ROCK to inactivate Rac1 [101]. The gene encoding Arhgap24 protein mutated in FSGS, and this mutation reduced the ability of Arhgap24 protein to convert Rac1 to an inactive state. The increased Rac1 activity in podocytes resulted in altered podocyte cell shape and membrane dynamics, and ultimately led to podocyte injury and proteinuria [102]. Additionally, ARHGDIA mutations [103] and ARHGEF17 mutations [104] (the genes encoding GDI and GEF, respectively) were also found in FSGS, both of which were closely relevant to the pathogenesis of FSGS (Figure 1), confirming that increased Rac1 activity was essential for podocyte injury and proteinuria.

Excluding the fact that mutations in genes encoding regulatory proteins increased the activity of Rac1 and Cdc42, other factors also triggered altered activities of these two molecules when mediating podocyte injury and proteinuria.

\subsection{Podocyte Injury and Transient Receptor Potential (TRP) Channels}

Actin cytoskeletal remodeling is a calcium ion-dependent process; transient receptor potential (TRP) channels can generate calcium ion microdomains in many cell types and therefore participate in this process [105]. Among the TRPCs, TRPC5 and TRPC6 are the ones commonly studied in podocyte injury and Rho family GTPases are closely involved in TRPC-mediated podocyte injury. The calcium influx mediated by the activation of TRPC5 and TRPC 6 in podocytes can antagonistically regulate actin dynamics and cell motility by stimulating the activation of Rac1 and RhoA, respectively [105]. The balance of calcium signals through TRPC 5 and TRPC 6 seems to be important to normal podocyte structure and function. Under physiologic conditions, the activation of TRPC6 is greater than that of TRPC5. Excessive activation of both TRPC6 and TRPC5 leads to podocyte injury and proteinuria [106]. TRPC6 expression has been found to be increased in patients with several acquired nephropathies [107]. TRPC5 can lead to podocyte injury and proteinuria 
through interaction with Rac1. The activation of Rac1 promoted the insertion of receptoractivated TRPC 5 into the plasma membrane of podocytes [105,108]. Under the activation of angiotensin II type 1 receptor (AT1R), calcium influx mediated by TRPC 5 further stimulated Rac1 activation, resulting in a positive feedback that led to podocyte actin cytoskeletal remodeling and foot process effacement. Both TRPC5 inhibitor AC1903 and Rac1 inhibitor alleviated the podocyte apoptosis and proteinuria induced by constitutively activated AT1R in podocytes $[109,110]$. However, a recent study found that TRPC5 was not involved in the occurrence or aggravation of kidney disease [111]. These two studies had completely opposite results. A discussion proposed that TRPC5 mutation has not been identified in human kidney diseases, which means the role of TRPC5 in podocyte injury and kidney disease remains to be clarified [112].

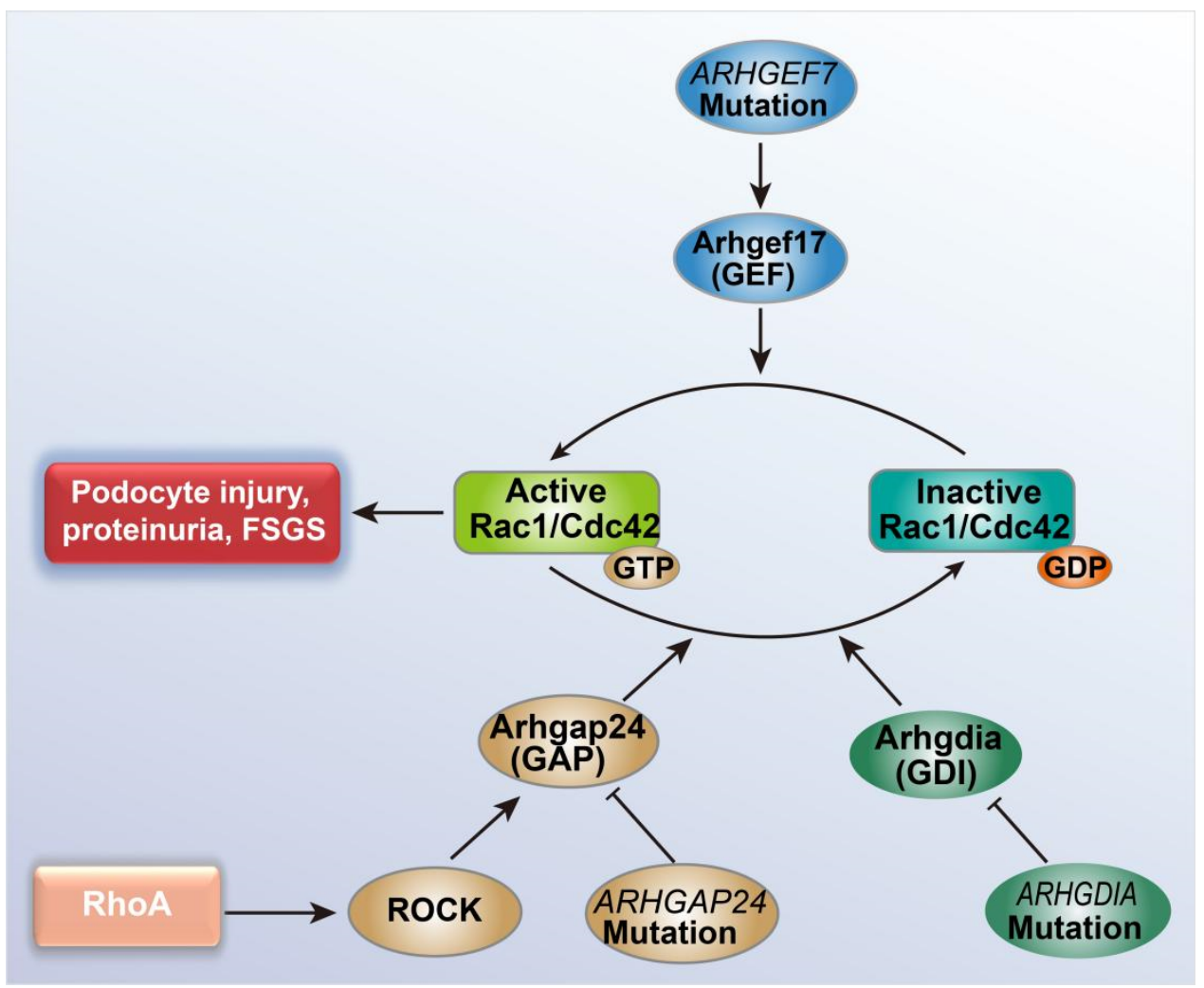

Figure 1. The relationship between FSGS and Rac1/Cdc42 activity transition. Rac1/Cdc42 changes from the GDP binding-inactive state to the GTP binding-activated state, which can cause FSGS characterized by podocyte damage and proteinuria. RhoA can activate GTPase activating protein Arhgap24 through its effector Rho kinase ROCK to inhibit this conversion. The ARHGAP24, ARHGDIA, and ARHGEF17 gene mutations in FSGS can increase the activity of Rac1/Cdc42 by inhibiting GAP activity and promoting GEF activity, respectively. Abbreviations: FSGS, focal segmental glomerulosclerosis; Arhgap24, Rho GTPase activating protein 24; GAP, GTPase activating protein; ROCK, Rho-associated kinase; Arhgdia, Rho GDP-dissociation inhibitor; GDI, GDP-dissociation inhibitor; Arhgef17, Rho Guanine Nucleotide Exchange Factor17; GEF, guanine nucleotide exchange factor.

\subsection{Podocyte Injury and Synaptopodin}

Synaptopodin plays an important role in the maintenance of the integrity of the podocyte actin cytoskeleton. In this process, synaptopodin is closely associated with the Rho family GTPases (Figure 2). It can competitively inhibit Smurf1-mediated RhoA ubiquitination, preventing it from degradation by proteasomes [97]. Synaptopodin can also alleviate podocyte injury and proteinuria caused by the Cdc42:IRSp53: Mena signaling complexes by competitively binding to insulin receptor substrate 53 (IRSp53) and blocking the binding of Cdc42 and Mena to IRSp53 [98]. Additionally, synaptopodin can inhibit 
Rac1 activity by inhibiting the activation of Vav2 (GEF) [100]. The calcium ion-dependent calcineurin can mediate the dephosphorylation of synaptopodin, thereby destroying the phosphorylation-dependent interaction between synaptopodin and 14-3-3 $\beta$, making synaptopodin suffer from cathepsin L (CatL)-mediated degradation [113]. Cyclosporine A (CsA) maintained the stability of the podocyte actin cytoskeleton by blocking the effect of calcineurin on synaptopodin [113], and alleviated the proteinuria caused by FSGS [114]. The relationship between synaptopodin and the Rho family GTPases suggests that patients may gain a similar benefit as from CsA - reducing proteinuria due to the inhibition of Rac1 and Cdc42 activity—but without suffering from the side effects of CsA.

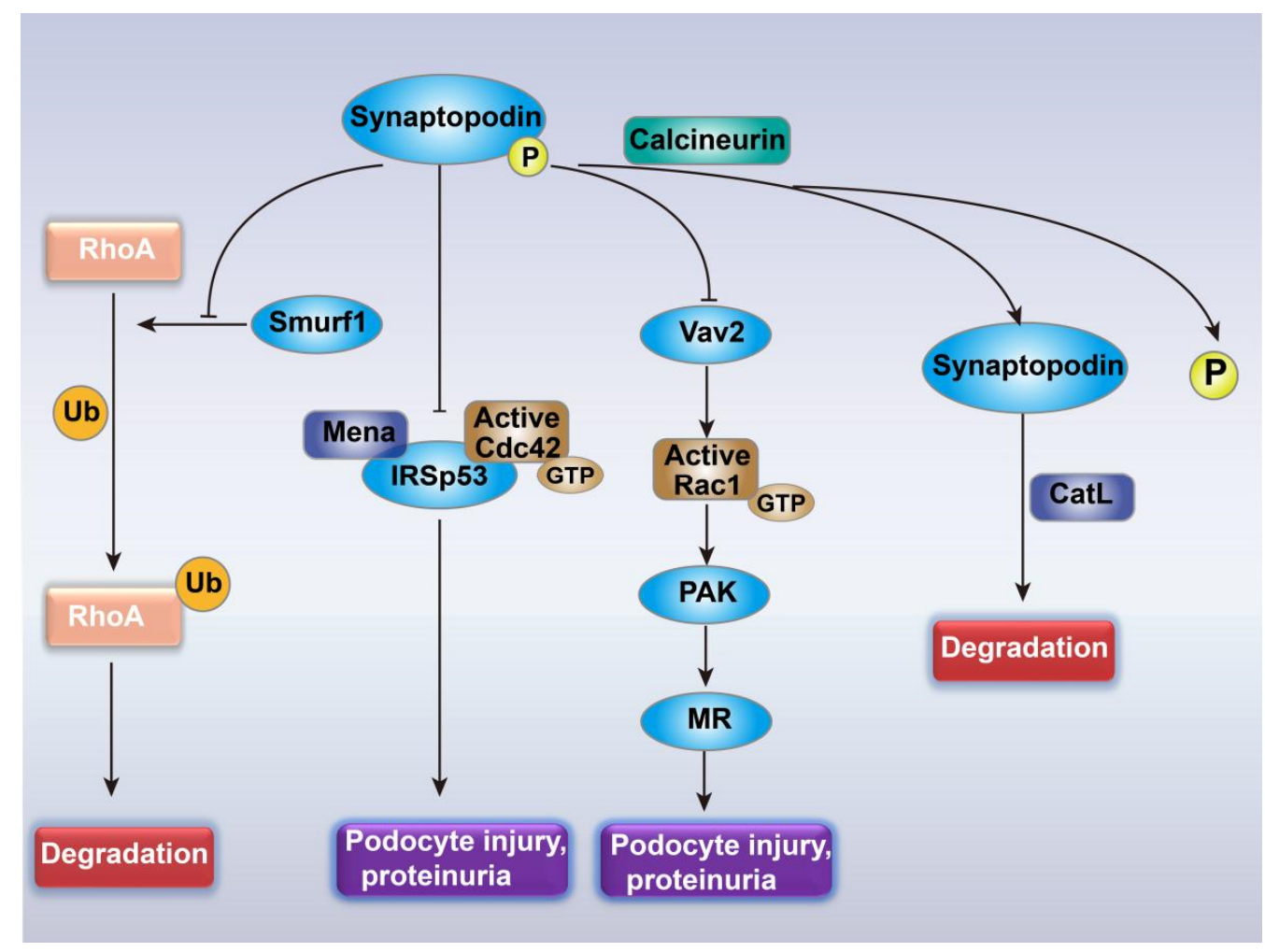

Figure 2. The connection between proteinuria and Rho GTPase family. Abbreviations: CatL, cathepsin L; Mena, an Ena/VASP family protein; IRSp53, insulin receptor substrate 53; Smurf1, smad ubiquitination regulatory factor 1; Vav2, a guanine nucleotide exchange factor; PAK, p21-activated kinase; $\mathrm{MR}$, mineralocorticoid receptor. $\mathrm{P}$, phosphorylation; $\mathrm{Ub}$, ubiquitination.

\subsection{Mineralocorticoid Receptor (MR)-Mediated Podocyte Injury}

Many drugs reduce proteinuria by inhibiting the renin-angiotensin-aldosterone system (RAAS) [12,13,115]; mineralocorticoid receptor (MR) antagonists Esaxerenone and Finerenone have also shown good effects in reducing proteinuria in clinical trials $[116,117]$. However, aldosterone is not the only stimulus that increases the expression of MR in patients with proteinuria; factors outside the RAAS system can also mediate the increased expression and activation of MR. A previous study quantified the serum aldosterone and mRNA expression level of MR in renal biopsies from 95 patients with mild to heavy proteinuria and found that serum aldosterone level was not related to MR mRNA expression or proteinuria; the mRNA expression of MR significantly increased in patients with heavy proteinuria when compared with patients with no proteinuria or mild proteinuria [118]. Further studies found that Rac1 promoted the expression of MR mRNA and protein in an aldosterone-independent manner and facilitated MR nuclear translocation and activation through p21-activated kinase (PAK) phosphorylation, which in turn caused podocyte damage and proteinuria (Figure 2) [99]. The administration of a Rac1 inhibitor significantly 
reduced the enhanced MR signal transduction in kidneys of Arhgdia-/-mice and alleviated proteinuria [99].

\subsection{Podocyte Damage and Proteinuria Mediated by the $u P A R-\alpha v \beta 3$ Pathway}

Increased podocyte motility is the potential mechanism leading to foot process effacement [102]. Urokinase receptor (uPAR), a molecule associated with cell motility, was therefore identified as the target for researching the mechanism of proteinuria. The results showed that UPAR expression was significantly elevated in podocytes of patients with FSGS and diabetic nephropathy characterized by foot process effacement and proteinuria [119]. In rodent proteinuric diseases with elevated UPAR expression, $\beta 3$ integrin was found to be activated by $\mathrm{UPAR}$ through vitronectin in the lipid-rich region of the podocyte plasma membrane and the inhibition of $\alpha \mathrm{v} \beta 3$ integrin not only reduced podocyte motility and proteinuria, but also decreased the elevation of Cdc42 and Rac1 activities (Figure 3) [119]. This indicated that the increased expression of UPAR in podocytes increased the activity of Cdc42 and Rac1 by activating $\alpha \mathrm{v} \beta 3$ integrin on the surface of podocytes, leading to increased podocyte motility, foot process effacement, and proteinuria [119].

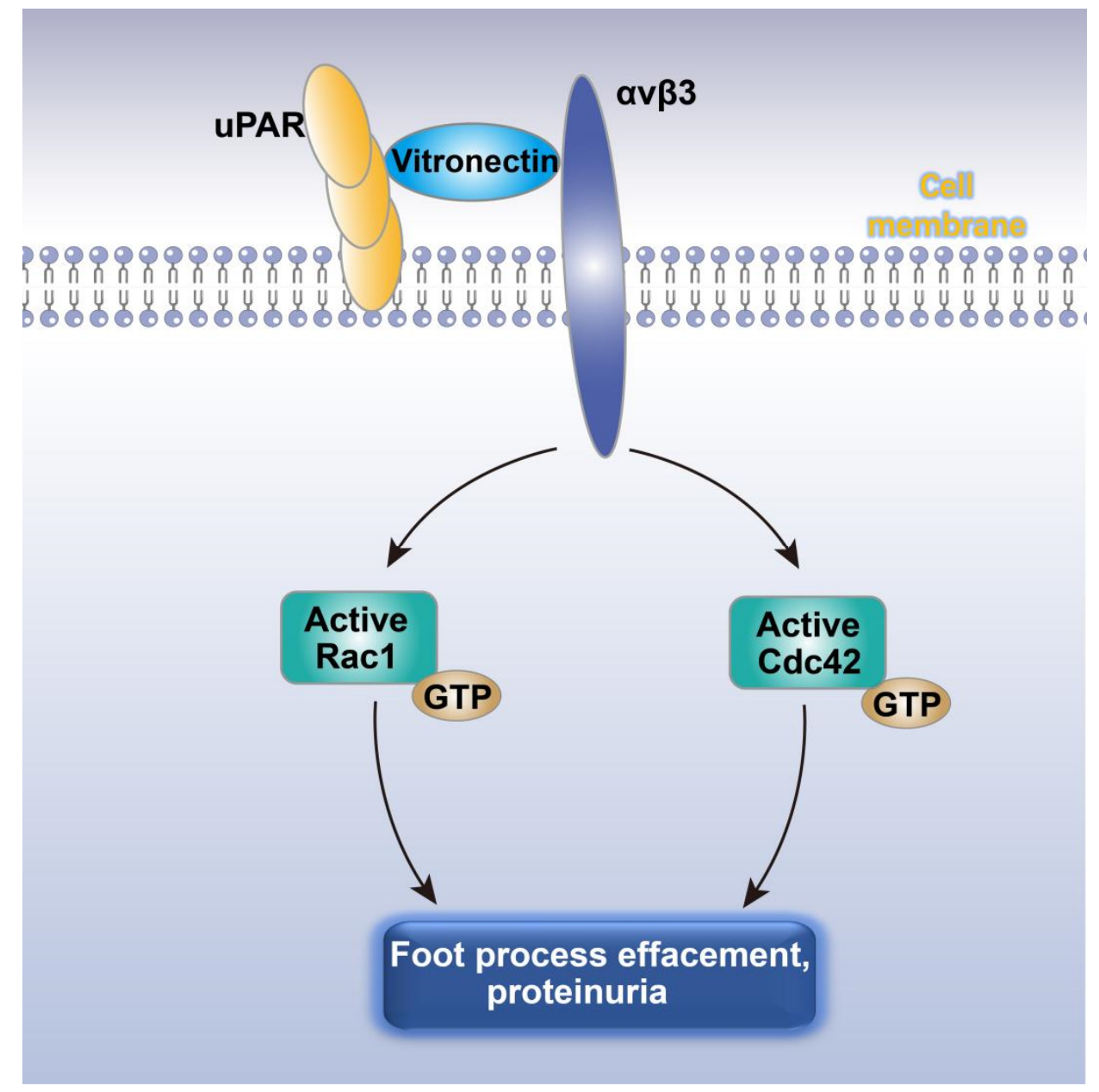

Figure 3. $u P A R-\alpha v \beta 3$ pathway mediated foot process effacement and proteinuria through Rac1 and Cdc42. uPAR activates $\alpha \mathrm{v} \beta 3$ integrin through vitronectin in the lipid-rich domain of the plasma membrane of podocytes, mediates the increase in Cdc42 and Rac1 activity, and induces foot process fusion and proteinuria. uPRA, urokinase receptor.

In addition, ILK has been proven to regulate the actin cytoskeleton through a complex composed of ILK, PINCH, and parvin [120,121], among which parvin can bind to $\alpha$-PIX (GEF); this complex can, therefore, regulate the Rac1 and Cdc42 activity [120]. 
Rac1 and Cdc42 are closely correlated with both angiogenesis and podocyte damage, indicating that compensatory pro-angiogenic factors produced by the kidneys of patients taking TKIs can theoretically act on diverse cells through Rac1 and Cdc42 at the same time, triggering different pathological phenotypes and clinical phenotypes. What is more, podocyte foot process effacement is reversible [94]. During the progression of FSGS, the threshold of podocyte apoptosis for glomerular injury irreversibility is $25-40 \%$ of the initial podocyte number. If the stimuli are removed before this threshold, glomerular damage and proteinuria can be completely reversed $[35,122]$. Therefore, in the early stage of proteinuria caused by TKIs, it may be feasible to reverse proteinuria and podocyte injury by inhibiting the activities of Cdc42 and Rac1.

\subsection{Molecules Involved in Angiogenesis and Podocyte Damage through Rac1 and Cdc42}

When considering the role of compensatory pro-angiogenic factors induced by TKIs in angiogenesis, vascular barrier repair, and podocyte injury through Rac1 and Cdc42, Notch1 seems to be a candidate. In maintaining vascular barrier function, the transmembrane domain of Notch1 was revealed due to Notch1 ligand Dll4-dependent proteolytic activation, which was triggered by hemodynamic shear stress. This transmembrane domain catalyzed the formation of a receptor complex consisting of vascular endothelial cadherin, transmembrane protein tyrosine phosphatase LAR and Rac1 GEF Trio in the plasma membrane, which drove adhesion junction assembly and restored the barrier function by activating Rac1 [123]. In the axon growth and guidance of Drosophila, Notch also activated Rac through Trio [124]. On the contrary, in murine proteinuric nephropathy models, the podocyte-specific deletion of Sirt6 exacerbated podocyte injury and proteinuria [125]. In normal podocytes, Sirt6 inhibited the transcription of Notch1 and Notch4 by deacetylating H3K9, which protected podocytes from inflammation and apoptosis, and maintained the stability of the actin cytoskeleton [125]. More studies need to be conducted to further verify whether the downregulation of Notch1 expression reduces proteinuria through the decreased Rac1 activity. Furthermore, the change in Notch1 signaling after TKI treatment remains unclear. Solving these problems will contribute to clarifying the mechanism of proteinuria related to antiangiogenic therapy.

\section{Podocyte Actin Cytoskeleton Regulatory Proteins}

The molecules produced by damaged endothelial cells may also lead to podocyte injury through affecting proteins that regulate actin cytoskeleton, such as nephrin, $\alpha$-actinin 4 , synaptopodin, etc. [67].

The regulation of the podocyte actin cytoskeleton by synaptopodin has been described above. In normal podocytes, the administration of VEGFR2 TKI decreased the level of synaptopodin and increased the expression of TGF- $\beta$ [74]. A recent study found that the glomerular injury induced by sorafenib (a multitarget TKI) was correlated with the decreased expression of synaptopodin, nephrin, podocin, and podoplanin [126].

Sorafenib may mediate proteinuria by blocking the downstream signaling pathway of nephrin through upregulating c-mip as well. Nephrin is a transmembrane protein expressed exclusively by the podocytes in the kidneys; it plays an important role in maintaining the integrity of the glomerular filtration barrier [67]. Under normal circumstances, the binding of activated Src family protein tyrosine kinase Fyn in the cell membrane to the cytoplasmic domain of nephrin promoted its phosphorylation. The phosphorylation of nephrin, on the one hand, triggered downstream phosphorylation events involving Nck, PAK-2, and N-WASP which promoted actin polymerization and cytoskeletal rearrangement; on the other hand, they activated Akt signaling pathway [127]. Sorafenib induced the overexpression of c-mip [28], which has been proven to reduce nephrin phosphorylation by directly binding to Fyn and preventing Fyn from interacting with nephrin and N-WASP [127]. Akt2 has been confirmed to have an inherent protective function in podocytes, and its knockout aggravated glomerulosclerosis and proteinuria by enhancing Rac1 activity [128]. Whether nephrin and AKT signaling pathway are involved in 
endothelial-podocyte crosstalk in proteinuric nephropathies remains unclear. Activating the Akt signaling pathway may be feasible to protect podocytes and alleviate proteinuria, but the influence of its activation on the efficacy of TKIs due to its close relationship with the VEGFA/VEGFR2 signaling pathway cannot be ignored. This requires researchers to be very careful when using this method to treat proteinuria.

$\alpha$-actinin 4 can be phosphorylated under the stimulation of EGF, which decreases the binding of $\alpha$-actinin 4 with actin [129]. TGF- $\beta$ can promote the phosphorylation of $\alpha$-actinin 4 as well, leading to podocyte injury and proteinuria [130]. Hepatocyte growth factor (HGF) attenuated podocyte injury induced by puromycin aminonucleoside through inducing the restoration of $\alpha$-actinin 4 and WT1 expression [131]. In NSCLC that is initially sensitive to VEGFR TKI, the development of resistance to treatment correlated with the increased expression of HGF and the activation of its receptor, c-MET. Dual inhibition of VEGFR/c-MET signaling delayed the resistance of NSCLC to VEGFR TKI [132]. It seems that tumor patients developing proteinuria after TKI treatment cannot benefit from HGF, but this may partly explain the predictive role of TKI-induced proteinuria on anticancer efficacy $[133,134]$ - that is, patients with proteinuria may have low levels of HGF.

Other podocyte actin cytoskeleton regulatory proteins may also be involved in TKIinduced podocyte injury and proteinuria, but this requires further exploration.

\section{Treatment}

Many studies have been conducted on the treatment of proteinuric nephropathies, and a variety of agents have been proven to be good at reducing proteinuria [12,13,115-117,135-138], but most of them target the RAAS system and no drugs have been reported to be effective at improving the clinical outcome of proteinuric nephropathy induced by VEGFAVEGFR2 inhibitors.

Considering the reversibility and the role of podocyte injury in proteinuric nephropathies, the direct protection of podocytes during TKI therapy may prevent the occurrence of proteinuria. TRPC5 small-molecule inhibitor AC1903 has been confirmed to be effective at alleviating podocyte injury and proteinuria in ATIR-induced FSGS and hypertensioninduced FSGS through disrupting the Rac1-TRPC5 pathway in podocytes [109]. Another small molecule, Bis-T-23, showed the same effect in terms of reducing podocyte injury and proteinuria in diverse rodent models of proteinuric nephropathies [139]. Bis-T-23 protected podocytes by promoting the polymerization of dynamin, a large, multidomain GTPase that plays an important role in the regulation of the actin cytoskeleton [139]. Previous studies found that actin filaments, lipids, microtubules, and SH3-domain-containing proteins can promote dynamin oligomerizing into a higher-order structure [31] that can promote actin polymerization $[139,140]$. Podocyte-specific dynamin knockout presented massive proteinuria and podocyte foot process effacement [141]. These drugs alleviated proteinuria in various proteinuric kidney diseases by directly protecting podocytes and may be equally effective at relieving the proteinuria induced by TKIs.

Recent studies on Fructus arctii, a traditional herbal remedy used in treating diabetes and its complications, have found that its major component, arctigenin (ATG), reduces p65 NF- $\mathrm{kB}$ (also known as RelA)-mediated inflammation and Drebrin-1 (DBN1)-mediated podocyte injury by enhancing the activity of protein phosphatase 2 (PP2A) in podocytes, thereby protecting kidney function [142]. Previous studies have found that Rac1 can mediate renal inflammation, podocyte injury, and proteinuria by promoting the activation of NF- $\mathrm{KB}$ [94]. In fact, we have found the high expression of p65 NF- $\mathrm{kB}$ in mouse models of proteinuric renal disease caused by TKIs (unpublished data). This suggests that antiinflammatory therapy may be helpful for alleviating the proteinuria induced by VEGFAVEGFR2 inhibitors.

No matter what methods are taken to address the proteinuria induced by VEGFAVEGFR2 inhibitors, the tumor progression of patients must be taken into account. Treatment regimens must be carefully screened to safely and effectively attenuate proteinuria without 
exacerbating tumor progression. The key to solve this problem is to thoroughly investigate the mechanism of proteinuric nephropathy induced by VEGFA-VEGFR2 inhibitors.

\section{Conclusions}

In TKI-induced proteinuric kidney disease, podocyte injury may be a key factor, and endothelial cell damage may be the initial factor. TKI-induced endothelial cell damage leads to the compensatory expression of pro-angiogenic factors to repair vascular or promote angiogenesis. The compensatory pro-angiogenic factors result in podocyte injury by promoting the formation of abnormal endothelial-podocyte crosstalk. Rac1 and Cdc42 play a crucial role in podocyte injury, angiogenesis, and vascular barrier repair, making them the key molecules for exploring the pro-angiogenic factors involved in TKI-induced proteinuric nephropathy.

Funding: This research was funded by the National Natural Science Foundation of China (No. 81672884) and the National Science and Technology Major Project of China (No. 2017ZX10203207-004-005).

Conflicts of Interest: The authors declare no conflict of interest.

\section{References}

1. Jayson, G.C.; Kerbel, R.; Ellis, L.M.; Harris, A.L. Antiangiogenic therapy in oncology: Current status and future directions. Lancet 2016, 388, 518-529. [CrossRef]

2. Estrada, C.C.; Maldonado, A.; Mallipattu, S.K. Therapeutic Inhibition of VEGF Signaling and Associated Nephrotoxicities. J. Am. Soc. Nephrol. 2019, 30, 187-200. [CrossRef]

3. Riechelmann, R.P.; Leite, L.S.; Bariani, G.M.; Glasberg, J.; Rivelli, T.G.; da Fonseca, L.G.; Nebuloni, D.R.; Braghiroli, M.I.; Queiroz, M.A.; Isejima, A.M.; et al. Regorafenib in Patients with Antiangiogenic-Naïve and Chemotherapy-Refractory Advanced Colorectal Cancer: Results from a Phase IIb Trial. Oncologist 2019, 24, 1180-1187. [CrossRef] [PubMed]

4. Sato, J.; Satouchi, M.; Itoh, S.; Okuma, Y.; Niho, S.; Mizugaki, H.; Murakami, H.; Fujisaka, Y.; Kozuki, T.; Nakamura, K.; et al. Lenvatinib in patients with advanced or metastatic thymic carcinoma (REMORA): A multicentre, phase 2 trial. Lancet Oncol. 2020, 21, 843-850. [CrossRef]

5. Nakagawa, K.; Garon, E.B.; Seto, T.; Nishio, M.; Ponce Aix, S.; Paz-Ares, L.; Chiu, C.-H.; Park, K.; Novello, S.; Nadal, E.; et al. Ramucirumab plus erlotinib in patients with untreated, EGFR-mutated, advanced non-small-cell lung cancer (RELAY): A randomised, double-blind, placebo-controlled, phase 3 trial. Lancet Oncol. 2019, 20, 1655-1669. [CrossRef]

6. Li, J.; Qin, S.; Xu, J.; Xiong, J.; Wu, C.; Bai, Y.; Liu, W.; Tong, J.; Liu, Y.; Xu, R.; et al. Randomized, Double-Blind, Placebo-Controlled Phase III Trial of Apatinib in Patients With Chemotherapy-Refractory Advanced or Metastatic Adenocarcinoma of the Stomach or Gastroesophageal Junction. J. Clin. Oncol. Off. J. Am. Soc. Clin. Oncol. 2016, 34, 1448-1454. [CrossRef] [PubMed]

7. Zhang, Z.F.; Wang, T.; Liu, L.H.; Guo, H.Q. Risks of proteinuria associated with vascular endothelial growth factor receptor tyrosine kinase inhibitors in cancer patients: A systematic review and meta-analysis. PLoS ONE 2014, 9, e90135. [CrossRef] [PubMed]

8. Rini, B.I.; Melichar, B.; Ueda, T.; Grünwald, V.; Fishman, M.N.; Arranz, J.A.; Bair, A.H.; Pithavala, Y.K.; Andrews, G.I.; Pavlov, D.; et al. Axitinib with or without dose titration for first-line metastatic renal-cell carcinoma: A randomised double-blind phase 2 trial. Lancet. Oncol. 2013, 14, 1233-1242. [CrossRef]

9. Zhu, X.; Wu, S.; Dahut, W.L.; Parikh, C.R. Risks of proteinuria and hypertension with bevacizumab, an antibody against vascular endothelial growth factor: Systematic review and meta-analysis. Am. J. Kidney Dis. Off. J. Natl. Kidney Found. 2007, 49, 186-193. [CrossRef] [PubMed]

10. Zhu, A.X.; Kang, Y.K.; Yen, C.J.; Finn, R.S.; Galle, P.R.; Llovet, J.M.; Assenat, E.; Brandi, G.; Pracht, M.; Lim, H.Y.; et al. Ramucirumab after sorafenib in patients with advanced hepatocellular carcinoma and increased $\alpha$-fetoprotein concentrations (REACH-2): A randomised, double-blind, placebo-controlled, phase 3 trial. Lancet. Oncol. 2019, 20, 282-296. [CrossRef]

11. Rini, B.I.; Plimack, E.R.; Stus, V.; Gafanov, R.; Hawkins, R.; Nosov, D.; Pouliot, F.; Alekseev, B.; Soulières, D.; Melichar, B.; et al. Pembrolizumab plus Axitinib versus Sunitinib for Advanced Renal-Cell Carcinoma. N. Engl. J. Med. 2019, 380, $1116-1127$. [CrossRef]

12. Haller, H.; Ito, S.; Izzo, J.L., Jr.; Januszewicz, A.; Katayama, S.; Menne, J.; Mimran, A.; Rabelink, T.J.; Ritz, E.; Ruilope, L.M.; et al. Olmesartan for the delay or prevention of microalbuminuria in type 2 diabetes. N. Engl. J. Med. 2011, 364, 907-917. [CrossRef]

13. Viberti, G.; Wheeldon, N.M. Microalbuminuria reduction with valsartan in patients with type 2 diabetes mellitus: A blood pressure-independent effect. Circulation 2002, 106, 672-678. [CrossRef] [PubMed]

14. Xu, Z.G.; Lanting, L.; Vaziri, N.D.; Li, Z.; Sepassi, L.; Rodriguez-Iturbe, B.; Natarajan, R. Upregulation of angiotensin II type 1 receptor, inflammatory mediators, and enzymes of arachidonate metabolism in obese Zucker rat kidney: Reversal by angiotensin II type 1 receptor blockade. Circulation 2005, 111, 1962-1969. [CrossRef] [PubMed] 
15. Hiramatsu, N.; Hiromura, K.; Shigehara, T.; Kuroiwa, T.; Ideura, H.; Sakurai, N.; Takeuchi, S.; Tomioka, M.; Ikeuchi, H.; Kaneko, Y.; et al. Angiotensin II type 1 receptor blockade inhibits the development and progression of HIV-associated nephropathy in a mouse model. J. Am. Soc. Nephrol. 2007, 18, 515-527. [CrossRef] [PubMed]

16. Roncone, D.; Satoskar, A.; Nadasdy, T.; Monk, J.P.; Rovin, B.H. Proteinuria in a patient receiving anti-VEGF therapy for metastatic renal cell carcinoma. Nat. Clin. Pract. Nephrol. 2007, 3, 287-293. [CrossRef]

17. Zhang, S.; Cao, M.; Hou, Z.; Gu, X.; Chen, Y.; Chen, L.; Luo, Y.; Chen, L.; Liu, D.; Zhou, H.; et al. Angiotensin-converting enzyme inhibitors have adverse effects in anti-angiogenesis therapy for hepatocellular carcinoma. Cancer Lett. 2021, 501, 147-161. [CrossRef]

18. Emile, G.; Pujade-Lauraine, E.; Alexandre, J. Should we use the angiotensin-converting enzyme inhibitors for the treatment of anti-VEGF-induced hypertension? Ann. Oncol. Off. J. Eur. Soc. Med. Oncol. 2014, 25, 1669-1670. [CrossRef]

19. Llovet, J.M.; Montal, R.; Sia, D.; Finn, R.S. Molecular therapies and precision medicine for hepatocellular carcinoma. Nat. Rev. Clin. Oncol. 2018, 15, 599-616. [CrossRef] [PubMed]

20. Norden, A.D.; Drappatz, J.; Wen, P.Y. Novel anti-angiogenic therapies for malignant gliomas. Lancet. Neurol. 2008, 7, 1152-1160. [CrossRef]

21. Gild, M.L.; Bullock, M.; Robinson, B.G.; Clifton-Bligh, R. Multikinase inhibitors: A new option for the treatment of thyroid cancer. Nat. Rev. Endocrinol. 2011, 7, 617-624. [CrossRef]

22. Zhou, J.; Goh, B.C.; Albert, D.H.; Chen, C.S. ABT-869, a promising multi-targeted tyrosine kinase inhibitor: From bench to bedside. J. Hematol. Oncol. 2009, 2, 33. [CrossRef]

23. Bukowski, R.M.; Yasothan, U.; Kirkpatrick, P. Pazopanib. Nat. Rev. Drug Discov. 2010, 9, 17-18. [CrossRef] [PubMed]

24. Eremina, V.; Sood, M.; Haigh, J.; Nagy, A.; Lajoie, G.; Ferrara, N.; Gerber, H.P.; Kikkawa, Y.; Miner, J.H.; Quaggin, S.E. Glomerularspecific alterations of VEGF-A expression lead to distinct congenital and acquired renal diseases. J. Clin. Investig. 2003, 111, 707-716. [CrossRef]

25. Eremina, V.; Jefferson, J.A.; Kowalewska, J.; Hochster, H.; Haas, M.; Weisstuch, J.; Richardson, C.; Kopp, J.B.; Kabir, M.G.; Backx, P.H.; et al. VEGF inhibition and renal thrombotic microangiopathy. N. Engl. J. Med. 2008, 358, 1129-1136. [CrossRef]

26. Izzedine, H.; Escudier, B.; Lhomme, C.; Pautier, P.; Rouvier, P.; Gueutin, V.; Baumelou, A.; Derosa, L.; Bahleda, R.; Hollebecque, A.; et al. Kidney diseases associated with anti-vascular endothelial growth factor (VEGF): An 8-year observational study at a single center. Medicine 2014, 93, 333-339. [CrossRef]

27. Ruebner, R.L.; Copelovitch, L.; Evageliou, N.F.; Denburg, M.R.; Belasco, J.B.; Kaplan, B.S. Nephrotic syndrome associated with tyrosine kinase inhibitors for pediatric malignancy: Case series and review of the literature. Pediatric Nephrol. 2014, 29, 863-869. [CrossRef]

28. Izzedine, H.; Mangier, M.; Ory, V.; Zhang, S.Y.; Sendeyo, K.; Bouachi, K.; Audard, V.; Pechoux, C.; Soria, J.C.; Massard, C.; et al. Expression patterns of RelA and c-mip are associated with different glomerular diseases following anti-VEGF therapy. Kidney Int. 2014, 85, 457-470. [CrossRef]

29. Siddiqi, F.S.; Advani, A. Endothelial-podocyte crosstalk: The missing link between endothelial dysfunction and albuminuria in diabetes. Diabetes 2013, 62, 3647-3655. [CrossRef]

30. D'Agati, V.D.; Kaskel, F.J.; Falk, R.J. Focal segmental glomerulosclerosis. N. Engl. J. Med. 2011, 365, 2398-2411. [CrossRef]

31. Sever, S.; Schiffer, M. Actin dynamics at focal adhesions: A common endpoint and putative therapeutic target for proteinuric kidney diseases. Kidney Int. 2018, 93, 1298-1307. [CrossRef]

32. D'Agati, V.D. Podocyte injury in focal segmental glomerulosclerosis: Lessons from animal models (a play in five acts). Kidney Int. 2008, 73, 399-406. [CrossRef] [PubMed]

33. Advani, A.; Kelly, D.J.; Advani, S.L.; Cox, A.J.; Thai, K.; Zhang, Y.; White, K.E.; Gow, R.M.; Marshall, S.M.; Steer, B.M.; et al. Role of VEGF in maintaining renal structure and function under normotensive and hypertensive conditions. Proc. Natl. Acad. Sci. USA 2007, 104, 14448-14453. [CrossRef]

34. Leeuwis, J.W.; Nguyen, T.Q.; Dendooven, A.; Kok, R.J.; Goldschmeding, R. Targeting podocyte-associated diseases. Adv. Drug Deliv. Rev. 2010, 62, 1325-1336. [CrossRef]

35. Daehn, I.; Casalena, G.; Zhang, T.; Shi, S.; Fenninger, F.; Barasch, N.; Yu, L.; D’Agati, V.; Schlondorff, D.; Kriz, W.; et al. Endothelial mitochondrial oxidative stress determines podocyte depletion in segmental glomerulosclerosis. J. Clin. Investig. 2014, 124, 1608-1621. [CrossRef]

36. Bartlett, C.S.; Jeansson, M.; Quaggin, S.E. Vascular Growth Factors and Glomerular Disease. Annu. Rev. Physiol. 2016, 78, 437-461. [CrossRef]

37. Babapoor-Farrokhran, S.; Jee, K.; Puchner, B.; Hassan, S.J.; Xin, X.; Rodrigues, M.; Kashiwabuchi, F.; Ma, T.; Hu, K.; Deshpande, M.; et al. Angiopoietin-like 4 is a potent angiogenic factor and a novel therapeutic target for patients with proliferative diabetic retinopathy. Proc. Natl. Acad. Sci. USA 2015, 112, e3030-e3039. [CrossRef]

38. Holderfield, M.T.; Hughes, C.C. Crosstalk between vascular endothelial growth factor, notch, and transforming growth factor-beta in vascular morphogenesis. Circ. Res. 2008, 102, 637-652. [CrossRef]

39. Clement, L.C.; Macé, C.; Avila-Casado, C.; Joles, J.A.; Kersten, S.; Chugh, S.S. Circulating angiopoietin-like 4 links proteinuria with hypertriglyceridemia in nephrotic syndrome. Nat. Med. 2014, 20, 37-46. [CrossRef]

40. Bondeva, T.; Wolf, G. Role of Neuropilin-1 in Diabetic Nephropathy. J. Clin. Med. 2015, 4, 1293-1311. [CrossRef] 
41. Loeffler, I.; Rüster, C.; Franke, S.; Liebisch, M.; Wolf, G. Erythropoietin ameliorates podocyte injury in advanced diabetic nephropathy in the db/db mouse. Am. J. Physiol. Ren. Physiol. 2013, 305, F911-F918. [CrossRef]

42. Parikh, S.M. The Angiopoietin-Tie2 Signaling Axis in Systemic Inflammation. J. Am. Soc. Nephrol. 2017, 28, 1973-1982. [CrossRef]

43. Dessapt-Baradez, C.; Woolf, A.S.; White, K.E.; Pan, J.; Huang, J.L.; Hayward, A.A.; Price, K.L.; Kolatsi-Joannou, M.; Locatelli, M.; Diennet, M.; et al. Targeted glomerular angiopoietin-1 therapy for early diabetic kidney disease. J. Am. Soc. Nephrol. 2014, 25, 33-42. [CrossRef]

44. Jian, W.; Levitt, J.M.; Lerner, S.P.; Sonpavde, G. The angiopoietin-TIE2 pathway is a potential therapeutic target in urothelial carcinoma. Anticancer Res. 2014, 34, 3377-3382.

45. Winkler, F.; Kozin, S.V.; Tong, R.T.; Chae, S.S.; Booth, M.F.; Garkavtsev, I.; Xu, L.; Hicklin, D.J.; Fukumura, D.; di Tomaso, E.; et al. Kinetics of vascular normalization by VEGFR2 blockade governs brain tumor response to radiation: Role of oxygenation, angiopoietin-1, and matrix metalloproteinases. Cancer Cell 2004, 6, 553-563. [CrossRef]

46. Bollée, G.; Flamant, M.; Schordan, S.; Fligny, C.; Rumpel, E.; Milon, M.; Schordan, E.; Sabaa, N.; Vandermeersch, S.; Galaup, A.; et al. Epidermal growth factor receptor promotes glomerular injury and renal failure in rapidly progressive crescentic glomerulonephritis. Nat. Med. 2011, 17, 1242-1250. [CrossRef]

47. Ma, X.; Schwarz, A.; Sevilla, S.Z.; Levin, A.; Hultenby, K.; Wernerson, A.; Lal, M.; Patrakka, J. Depletion of Gprc5a Promotes Development of Diabetic Nephropathy. J. Am. Soc. Nephrol. 2018, 29, 1679-1689. [CrossRef]

48. Chen, J.; Chen, J.K.; Harris, R.C. EGF receptor deletion in podocytes attenuates diabetic nephropathy. J. Am. Soc. Nephrol. 2015, 26, 1115-1125. [CrossRef]

49. Tang, J.; Liu, N.; Zhuang, S. Role of epidermal growth factor receptor in acute and chronic kidney injury. Kidney Int. 2013, 83, 804-810. [CrossRef]

50. Tapia, R.; Guan, F.; Gershin, I.; Teichman, J.; Villegas, G.; Tufro, A. Semaphorin3a disrupts podocyte foot processes causing acute proteinuria. Kidney Int. 2008, 73, 733-740. [CrossRef]

51. Maione, F.; Capano, S.; Regano, D.; Zentilin, L.; Giacca, M.; Casanovas, O.; Bussolino, F.; Serini, G.; Giraudo, E. Semaphorin 3A overcomes cancer hypoxia and metastatic dissemination induced by antiangiogenic treatment in mice. J. Clin. Investig. 2012, 122, 1832-1848. [CrossRef]

52. Yamada, D.; Watanabe, S.; Kawahara, K.; Maeda, T. Plexin A1 signaling confers malignant phenotypes in lung cancer cells. Biochem. Biophys. Res. Commun. 2016, 480, 75-80. [CrossRef]

53. Takabatake, Y.; Sugiyama, T.; Kohara, H.; Matsusaka, T.; Kurihara, H.; Koni, P.A.; Nagasawa, Y.; Hamano, T.; Matsui, I.; Kawada, N.; et al. The CXCL12 (SDF-1)/CXCR4 axis is essential for the development of renal vasculature. J. Am. Soc. Nephrol. 2009, 20, 1714-1723. [CrossRef]

54. Petit, I.; Jin, D.; Rafii, S. The SDF-1-CXCR4 signaling pathway: A molecular hub modulating neo-angiogenesis. Trends Immunol. 2007, 28, 299-307. [CrossRef]

55. Li, W.; Kohara, H.; Uchida, Y.; James, J.M.; Soneji, K.; Cronshaw, D.G.; Zou, Y.R.; Nagasawa, T.; Mukouyama, Y.S. Peripheral nerve-derived CXCL12 and VEGF-A regulate the patterning of arterial vessel branching in developing limb skin. Dev. Cell 2013, 24, 359-371. [CrossRef]

56. Sayyed, S.G.; Hägele, H.; Kulkarni, O.P.; Endlich, K.; Segerer, S.; Eulberg, D.; Klussmann, S.; Anders, H.J. Podocytes produce homeostatic chemokine stromal cell-derived factor-1/CXCL12, which contributes to glomerulosclerosis, podocyte loss and albuminuria in a mouse model of type 2 diabetes. Diabetologia 2009, 52, 2445-2454. [CrossRef]

57. Takashima, S.; Fujita, H.; Fujishima, H.; Shimizu, T.; Sato, T.; Morii, T.; Tsukiyama, K.; Narita, T.; Takahashi, T.; Drucker, D.J.; et al. Stromal cell-derived factor- 1 is upregulated by dipeptidyl peptidase- 4 inhibition and has protective roles in progressive diabetic nephropathy. Kidney Int. 2016, 90, 783-796. [CrossRef]

58. Pham, K.; Luo, D.; Siemann, D.W.; Law, B.K.; Reynolds, B.A.; Hothi, P.; Foltz, G.; Harrison, J.K. VEGFR inhibitors upregulate CXCR4 in VEGF receptor-expressing glioblastoma in a TGF $\beta R$ signaling-dependent manner. Cancer Lett. 2015, 360, 60-67. [CrossRef]

59. Gravina, G.L.; Mancini, A.; Marampon, F.; Colapietro, A.; Delle Monache, S.; Sferra, R.; Vitale, F.; Richardson, P.J.; Patient, L.; Burbidge, S.; et al. The brain-penetrating CXCR4 antagonist, PRX177561, increases the antitumor effects of bevacizumab and sunitinib in preclinical models of human glioblastoma. J. Hematol. Oncol. 2017, 10, 5. [CrossRef]

60. Schumacher, V.A.; Schlötzer-Schrehardt, U.; Karumanchi, S.A.; Shi, X.; Zaia, J.; Jeruschke, S.; Zhang, D.; Pavenstädt, H.; Drenckhan, A.; Amann, K.; et al. WT1-dependent sulfatase expression maintains the normal glomerular filtration barrier. J. Am. Soc. Nephrol. 2011, 22, 1286-1296. [CrossRef]

61. Gebeshuber, C.A.; Kornauth, C.; Dong, L.; Sierig, R.; Seibler, J.; Reiss, M.; Tauber, S.; Bilban, M.; Wang, S.; Kain, R.; et al. Focal segmental glomerulosclerosis is induced by microRNA-193a and its downregulation of WT1. Nat. Med. $2013,19,481-487$. [CrossRef]

62. Madhusudhan, T.; Kerlin, B.A.; Isermann, B. The emerging role of coagulation proteases in kidney disease. Nat. Rev. Nephrol. 2016, 12, 94-109. [CrossRef] [PubMed]

63. Gil-Bernabe, P.; D’Alessandro-Gabazza, C.N.; Toda, M.; Boveda Ruiz, D.; Miyake, Y.; Suzuki, T.; Onishi, Y.; Morser, J.; Gabazza, E.C.; Takei, Y.; et al. Exogenous activated protein C inhibits the progression of diabetic nephropathy. J. Thromb. Haemost. 2012, 10, 337-346. [CrossRef] [PubMed] 
64. Burnier, L.; Mosnier, L.O. Novel mechanisms for activated protein C cytoprotective activities involving noncanonical activation of protease-activated receptor 3. Blood 2013, 122, 807-816. [CrossRef] [PubMed]

65. Sundaram, J.; Keshava, S.; Gopalakrishnan, R.; Esmon, C.T.; Pendurthi, U.R.; Rao, L.V. Factor VIIa binding to endothelial cell protein C receptor protects vascular barrier integrity in vivo. J. Thromb. Haemost. 2014, 12, 690-700. [CrossRef] [PubMed]

66. Liu, Y. New insights into epithelial-mesenchymal transition in kidney fibrosis. J. Am. Soc. Nephrol. 2010, 21, 212-222. [CrossRef]

67. Pavenstädt, H.; Kriz, W.; Kretzler, M. Cell biology of the glomerular podocyte. Physiol. Rev. 2003, 83, 253-307. [CrossRef]

68. Dai, C.; Stolz, D.B.; Bastacky, S.I.; St-Arnaud, R.; Wu, C.; Dedhar, S.; Liu, Y. Essential role of integrin-linked kinase in podocyte biology: Bridging the integrin and slit diaphragm signaling. J. Am. Soc. Nephrol. 2006, 17, 2164-2175. [CrossRef]

69. Kang, Y.S.; Li, Y.; Dai, C.; Kiss, L.P.; Wu, C.; Liu, Y. Inhibition of integrin-linked kinase blocks podocyte epithelial-mesenchymal transition and ameliorates proteinuria. Kidney Int. 2010, 78, 363-373. [CrossRef]

70. Giacomini, A.; Taranto, S.; Rezzola, S.; Matarazzo, S.; Grillo, E.; Bugatti, M.; Scotuzzi, A.; Guerra, J.; Di Trani, M.; Presta, M.; et al. Inhibition of the FGF/FGFR System Induces Apoptosis in Lung Cancer Cells via c-Myc Downregulation and Oxidative Stress. Int. J. Mol. Sci. 2020, 21, 9376. [CrossRef]

71. Kappers, M.H.; Smedts, F.M.; Horn, T.; van Esch, J.H.; Sleijfer, S.; Leijten, F.; Wesseling, S.; Strevens, H.; Jan Danser, A.H.; van den Meiracker, A.H. The vascular endothelial growth factor receptor inhibitor sunitinib causes a preeclampsia-like syndrome with activation of the endothelin system. Hypertension 2011, 58, 295-302. [CrossRef]

72. Orcutt, K.P.; Parsons, A.D.; Sibenaller, Z.A.; Scarbrough, P.M.; Zhu, Y.; Sobhakumari, A.; Wilke, W.W.; Kalen, A.L.; Goswami, P.; Miller, F.J., Jr.; et al. Erlotinib-mediated inhibition of EGFR signaling induces metabolic oxidative stress through NOX4. Cancer Res. 2011, 71, 3932-3940. [CrossRef] [PubMed]

73. Wang, C.; Wang, T.; Lv, D.; Li, L.; Yue, J.; Chen, H.Z.; Xu, L. Acquired Resistance to EGFR TKIs Mediated by TGF $\beta 1 /$ Integrin $\beta 3$ Signaling in EGFR-Mutant Lung Cancer. Mol. Cancer Ther. 2019, 18, 2357-2367. [CrossRef]

74. Liu, X.; Zhang, H.; Wang, Q.; Yu, K.; Wang, R.; Sun, J. Blockade of vascular endothelial growth factor-A/receptor 2 exhibits a protective effect on angiotensin-II stimulated podocytes. Mol. Med. Rep. 2015, 12, 4340-4345. [CrossRef] [PubMed]

75. Sendeyo, K.; Audard, V.; Zhang, S.Y.; Fan, Q.; Bouachi, K.; Ollero, M.; Rucker-Martin, C.; Gouadon, E.; Desvaux, D.; Bridoux, F.; et al. Upregulation of c-mip is closely related to podocyte dysfunction in membranous nephropathy. Kidney Int. 2013, 83, 414-425. [CrossRef] [PubMed]

76. Raja, R.; Kale, S.; Thorat, D.; Soundararajan, G.; Lohite, K.; Mane, A.; Karnik, S.; Kundu, G.C. Hypoxia-driven osteopontin contributes to breast tumor growth through modulation of HIF1 $\alpha$-mediated VEGF-dependent angiogenesis. Oncogene 2014, 33, 2053-2064. [CrossRef]

77. Wani, A.A.; Jafarnejad, S.M.; Zhou, J.; Li, G. Integrin-linked kinase regulates melanoma angiogenesis by activating NFкB/interleukin-6 signaling pathway. Oncogene 2011, 30, 2778-2788. [CrossRef]

78. Wu, M.H.; Huang, C.Y.; Lin, J.A.; Wang, S.W.; Peng, C.Y.; Cheng, H.C.; Tang, C.H. Endothelin-1 promotes vascular endothelial growth factor-dependent angiogenesis in human chondrosarcoma cells. Oncogene 2014, 33, 1725-1735. [CrossRef]

79. Karachaliou, N.; Cardona, A.F.; Bracht, J.W.P.; Aldeguer, E.; Drozdowskyj, A.; Fernandez-Bruno, M.; Chaib, I.; Berenguer, J.; Santarpia, M.; Ito, M.; et al. Integrin-linked kinase (ILK) and src homology 2 domain-containing phosphatase 2 (SHP2): Novel targets in EGFR-mutation positive non-small cell lung cancer (NSCLC). EBioMedicine 2019, 39, 207-214. [CrossRef]

80. Ju, L.; Dong, Z.; Yang, J.; Li, M. Mechanism of intrinsic resistance of lung squamous cell carcinoma to epithelial growth factor receptor-tyrosine kinase inhibitors revealed by high-throughput RNA interference screening. Oncol. Lett. 2020, 20, 363. [CrossRef]

81. Wedel, S.; Hudak, L.; Seibel, J.M.; Makarević, J.; Juengel, E.; Tsaur, I.; Waaga-Gasser, A.; Haferkamp, A.; Blaheta, R.A. Molecular targeting of prostate cancer cells by a triple drug combination down-regulates integrin driven adhesion processes, delays cell cycle progression and interferes with the cdk-cyclin axis. BMC Cancer 2011, 11, 375. [CrossRef] [PubMed]

82. Galvan, D.L.; Green, N.H.; Danesh, F.R. The hallmarks of mitochondrial dysfunction in chronic kidney disease. Kidney Int. 2017, 92, 1051-1057. [CrossRef]

83. Nakanishi, T.; Kuragano, T.; Nanami, M.; Nagasawa, Y.; Hasuike, Y. Misdistribution of iron and oxidative stress in chronic kidney disease. Free Radic. Biol. Med. 2019, 133, 248-253. [CrossRef] [PubMed]

84. Emma, F.; Montini, G.; Parikh, S.M.; Salviati, L. Mitochondrial dysfunction in inherited renal disease and acute kidney injury. Nat. Rev. Nephrol. 2016, 12, 267-280. [CrossRef] [PubMed]

85. Su, M.; Dhoopun, A.R.; Yuan, Y.; Huang, S.; Zhu, C.; Ding, G.; Liu, B.; Yang, T.; Zhang, A. Mitochondrial dysfunction is an early event in aldosterone-induced podocyte injury. Am. J. Physiol. Ren. Physiol. 2013, 305, F520-F531. [CrossRef]

86. Dounousi, E.; Papavasiliou, E.; Makedou, A.; Ioannou, K.; Katopodis, K.P.; Tselepis, A.; Siamopoulos, K.C.; Tsakiris, D. Oxidative stress is progressively enhanced with advancing stages of CKD. Am. J. Kidney Dis. Off. J. Natl. Kidney Found. 2006, 48, 752-760. [CrossRef] [PubMed]

87. Jha, J.C.; Ho, F.; Dan, C.; Jandeleit-Dahm, K. A causal link between oxidative stress and inflammation in cardiovascular and renal complications of diabetes. Clin. Sci. 2018, 132, 1811-1836. [CrossRef]

88. Oberg, B.P.; McMenamin, E.; Lucas, F.L.; McMonagle, E.; Morrow, J.; Ikizler, T.A.; Himmelfarb, J. Increased prevalence of oxidant stress and inflammation in patients with moderate to severe chronic kidney disease. Kidney Int. 2004, 65, 1009-1016. [CrossRef] [PubMed] 
89. Witko-Sarsat, V.; Friedlander, M.; Capeillère-Blandin, C.; Nguyen-Khoa, T.; Nguyen, A.T.; Zingraff, J.; Jungers, P.; DescampsLatscha, B. Advanced oxidation protein products as a novel marker of oxidative stress in uremia. Kidney Int. 1996, 49, $1304-1313$. [CrossRef]

90. De Vecchi, A.F.; Bamonti, F.; Novembrino, C.; Ippolito, S.; Guerra, L.; Lonati, S.; Salini, S.; Aman, C.S.; Scurati-Manzoni, E.; Cighetti, G. Free and total plasma malondialdehyde in chronic renal insufficiency and in dialysis patients. Nephrol. Dial. Transplantat. 2009, 24, 2524-2529. [CrossRef]

91. Vanholder, R.; Argilés, A.; Baurmeister, U.; Brunet, P.; Clark, W.; Cohen, G.; De Deyn, P.P.; Deppisch, R.; Descamps-Latscha, B.; Henle, T.; et al. Uremic toxicity: Present state of the art. Int. J. Artif. Organs 2001, 24, 695-725. [CrossRef] [PubMed]

92. Qi, H.; Casalena, G.; Shi, S.; Yu, L.; Ebefors, K.; Sun, Y.; Zhang, W.; D’Agati, V.; Schlondorff, D.; Haraldsson, B.; et al. Glomerular Endothelial Mitochondrial Dysfunction Is Essential and Characteristic of Diabetic Kidney Disease Susceptibility. Diabetes 2017, 66, 763-778. [CrossRef]

93. Lamalice, L.; Le Boeuf, F.; Huot, J. Endothelial cell migration during angiogenesis. Circ. Res. 2007, 100, 782-794. [CrossRef] [PubMed]

94. Nagase, M.; Fujita, T. Role of Rac1-mineralocorticoid-receptor signalling in renal and cardiac disease. Nat. Rev. Nephrol. 2013, 9, 86-98. [CrossRef]

95. Rama, N.; Dubrac, A.; Mathivet, T.; RA, N.C.; Genet, G.; Cristofaro, B.; Pibouin-Fragner, L.; Ma, L.; Eichmann, A.; Chédotal, A. Slit2 signaling through Robo1 and Robo2 is required for retinal neovascularization. Nat. Med. 2015, 21, 483-491. [CrossRef] [PubMed]

96. Eelen, G.; Dubois, C.; Cantelmo, A.R.; Goveia, J.; Brüning, U.; DeRan, M.; Jarugumilli, G.; van Rijssel, J.; Saladino, G.; Comitani, F.; et al. Role of glutamine synthetase in angiogenesis beyond glutamine synthesis. Nature 2018, 561, 63-69. [CrossRef]

97. Asanuma, K.; Yanagida-Asanuma, E.; Faul, C.; Tomino, Y.; Kim, K.; Mundel, P. Synaptopodin orchestrates actin organization and cell motility via regulation of RhoA signalling. Nat. Cell Biol. 2006, 8, 485-491. [CrossRef]

98. Yanagida-Asanuma, E.; Asanuma, K.; Kim, K.; Donnelly, M.; Young Choi, H.; Hyung Chang, J.; Suetsugu, S.; Tomino, Y.; Takenawa, T.; Faul, C.; et al. Synaptopodin protects against proteinuria by disrupting Cdc42:IRSp53:Mena signaling complexes in kidney podocytes. Am. J. Pathol. 2007, 171, 415-427. [CrossRef]

99. Shibata, S.; Nagase, M.; Yoshida, S.; Kawarazaki, W.; Kurihara, H.; Tanaka, H.; Miyoshi, J.; Takai, Y.; Fujita, T. Modification of mineralocorticoid receptor function by Rac1 GTPase: Implication in proteinuric kidney disease. Nat. Med. 2008, 14, 1370-1376. [CrossRef]

100. Buvall, L.; Wallentin, H.; Sieber, J.; Andreeva, S.; Choi, H.Y.; Mundel, P.; Greka, A. Synaptopodin Is a Coincidence Detector of Tyrosine versus Serine/Threonine Phosphorylation for the Modulation of Rho Protein Crosstalk in Podocytes. J. Am. Soc. Nephrol. 2017, 28, 837-851. [CrossRef]

101. Ohta, Y.; Hartwig, J.H.; Stossel, T.P. FilGAP, a Rho- and ROCK-regulated GAP for Rac binds filamin A to control actin remodelling. Nat. Cell Biol. 2006, 8, 803-814. [CrossRef]

102. Akilesh, S.; Suleiman, H.; Yu, H.; Stander, M.C.; Lavin, P.; Gbadegesin, R.; Antignac, C.; Pollak, M.; Kopp, J.B.; Winn, M.P.; et al. Arhgap24 inactivates Rac1 in mouse podocytes, and a mutant form is associated with familial focal segmental glomerulosclerosis. J. Clin. Investig. 2011, 121, 4127-4137. [CrossRef]

103. Gee, H.Y.; Saisawat, P.; Ashraf, S.; Hurd, T.W.; Vega-Warner, V.; Fang, H.; Beck, B.B.; Gribouval, O.; Zhou, W.; Diaz, K.A.; et al. ARHGDIA mutations cause nephrotic syndrome via defective RHO GTPase signaling. J. Clin. Investig. 2013, 123, 3243-3253. [CrossRef]

104. Yu, H.; Artomov, M.; Brähler, S.; Stander, M.C.; Shamsan, G.; Sampson, M.G.; White, J.M.; Kretzler, M.; Miner, J.H.; Jain, S.; et al. A role for genetic susceptibility in sporadic focal segmental glomerulosclerosis. J. Clin. Investig. 2016, 126, 1603. [CrossRef]

105. Tian, D.; Jacobo, S.M.; Billing, D.; Rozkalne, A.; Gage, S.D.; Anagnostou, T.; Pavenstädt, H.; Hsu, H.H.; Schlondorff, J.; Ramos, A.; et al. Antagonistic regulation of actin dynamics and cell motility by TRPC5 and TRPC6 channels. Sci. Signal. 2010, 3, ra77. [CrossRef]

106. Greka, A.; Mundel, P. Balancing calcium signals through TRPC5 and TRPC6 in podocytes. J. Am. Soc. Nephrol. 2011, 22, 1969-1980. [CrossRef]

107. Ilatovskaya, D.V.; Staruschenko, A. TRPC6 channel as an emerging determinant of the podocyte injury susceptibility in kidney diseases. Am. J. Physiol. Ren. Physiol. 2015, 309, F393-F397. [CrossRef]

108. Bezzerides, V.J.; Ramsey, I.S.; Kotecha, S.; Greka, A.; Clapham, D.E. Rapid vesicular translocation and insertion of TRP channels. Nat. Cell Biol. 2004, 6, 709-720. [CrossRef]

109. Zhou, Y.; Castonguay, P.; Sidhom, E.H.; Clark, A.R.; Dvela-Levitt, M.; Kim, S.; Sieber, J.; Wieder, N.; Jung, J.Y.; Andreeva, S.; et al. A small-molecule inhibitor of TRPC5 ion channels suppresses progressive kidney disease in animal models. Science 2017, 358, 1332-1336. [CrossRef]

110. Schaldecker, T.; Kim, S.; Tarabanis, C.; Tian, D.; Hakroush, S.; Castonguay, P.; Ahn, W.; Wallentin, H.; Heid, H.; Hopkins, C.R.; et al. Inhibition of the TRPC5 ion channel protects the kidney filter. J. Clin. Investig. 2013, 123, 5298-5309. [CrossRef]

111. Wang, X.; Dande, R.R.; Yu, H.; Samelko, B.; Miller, R.E.; Altintas, M.M.; Reiser, J. TRPC5 Does Not Cause or Aggravate Glomerular Disease. J. Am. Soc. Nephrol. 2018, 29, 409-415. [CrossRef]

112. van der Wijst, J.; Bindels, R.J.M. Renal physiology: TRPC5 inhibition to treat progressive kidney disease. Nat. Rev. Nephrol. 2018, 14, 145-146. [CrossRef] 
113. Faul, C.; Donnelly, M.; Merscher-Gomez, S.; Chang, Y.H.; Franz, S.; Delfgaauw, J.; Chang, J.M.; Choi, H.Y.; Campbell, K.N.; Kim, K.; et al. The actin cytoskeleton of kidney podocytes is a direct target of the antiproteinuric effect of cyclosporine A. Nat. Med. 2008, 14, 931-938. [CrossRef] [PubMed]

114. Büscher, A.K.; Beck, B.B.; Melk, A.; Hoefele, J.; Kranz, B.; Bamborschke, D.; Baig, S.; Lange-Sperandio, B.; Jungraithmayr, T.; Weber, L.T.; et al. Rapid Response to Cyclosporin A and Favorable Renal Outcome in Nongenetic Versus Genetic Steroid-Resistant Nephrotic Syndrome. Clin. J. Am. Soc. Nephrol. 2016, 11, 245-253. [CrossRef] [PubMed]

115. Parving, H.H.; Persson, F.; Lewis, J.B.; Lewis, E.J.; Hollenberg, N.K. Aliskiren combined with losartan in type 2 diabetes and nephropathy. N. Engl. J. Med. 2008, 358, 2433-2446. [CrossRef] [PubMed]

116. Bakris, G.L.; Agarwal, R.; Chan, J.C.; Cooper, M.E.; Gansevoort, R.T.; Haller, H.; Remuzzi, G.; Rossing, P.; Schmieder, R.E.; Nowack, C.; et al. Effect of Finerenone on Albuminuria in Patients With Diabetic Nephropathy: A Randomized Clinical Trial. JAMA 2015, 314, 884-894. [CrossRef] [PubMed]

117. Ito, S.; Shikata, K.; Nangaku, M.; Okuda, Y.; Sawanobori, T. Efficacy and Safety of Esaxerenone (CS-3150) for the Treatment of Type 2 Diabetes with Microalbuminuria: A Randomized, Double-Blind, Placebo-Controlled, Phase II Trial. Clin. J. Am. Soc. Nephrol. 2019, 14, 1161-1172. [CrossRef]

118. Quinkler, M.; Zehnder, D.; Eardley, K.S.; Lepenies, J.; Howie, A.J.; Hughes, S.V.; Cockwell, P.; Hewison, M.; Stewart, P.M. Increased expression of mineralocorticoid effector mechanisms in kidney biopsies of patients with heavy proteinuria. Circulation 2005, 112, 1435-1443. [CrossRef]

119. Wei, C.; Möller, C.C.; Altintas, M.M.; Li, J.; Schwarz, K.; Zacchigna, S.; Xie, L.; Henger, A.; Schmid, H.; Rastaldi, M.P.; et al. Modification of kidney barrier function by the urokinase receptor. Nat. Med. 2008, 14, 55-63. [CrossRef] [PubMed]

120. Legate, K.R.; Montanez, E.; Kudlacek, O.; Fassler, R. ILK, PINCH and parvin: The tIPP of integrin signalling. Nat. Rev. Mol. Cell Biol. 2006, 7, 20-31. [CrossRef] [PubMed]

121. Vaynberg, J.; Fukuda, K.; Lu, F.; Bialkowska, K.; Chen, Y.; Plow, E.F.; Qin, J. Non-catalytic signaling by pseudokinase ILK for regulating cell adhesion. Nat. Commun. 2018, 9, 4465. [CrossRef]

122. Wharram, B.L.; Goyal, M.; Wiggins, J.E.; Sanden, S.K.; Hussain, S.; Filipiak, W.E.; Saunders, T.L.; Dysko, R.C.; Kohno, K.; Holzman, L.B.; et al. Podocyte depletion causes glomerulosclerosis: Diphtheria toxin-induced podocyte depletion in rats expressing human diphtheria toxin receptor transgene. J. Am. Soc. Nephrol. 2005, 16, 2941-2952. [CrossRef]

123. Polacheck, W.J.; Kutys, M.L.; Yang, J.; Eyckmans, J.; Wu, Y.; Vasavada, H.; Hirschi, K.K.; Chen, C.S. A non-canonical Notch complex regulates adherens junctions and vascular barrier function. Nature 2017, 552, 258-262. [CrossRef] [PubMed]

124. Song, J.K.; Giniger, E. Noncanonical Notch function in motor axon guidance is mediated by Rac GTPase and the GEF1 domain of Trio. Dev. Dyn. 2011, 240, 324-332. [CrossRef]

125. Liu, M.; Liang, K.; Zhen, J.; Zhou, M.; Wang, X.; Wang, Z.; Wei, X.; Zhang, Y.; Sun, Y.; Zhou, Z.; et al. Sirt6 deficiency exacerbates podocyte injury and proteinuria through targeting Notch signaling. Nat. Commun. 2017, 8, 413. [CrossRef] [PubMed]

126. Stavniichuk, A.; Savchuk, O.; Khan, A.H.; Jankiewicz, W.K.; Imig, J.D. A sorafenib induced model of glomerular kidney disease Visnyk Kyivskoho Natsionalnoho Universytetu Imeni Tarasa Shevchenka Biolohiia 2020, 81, 25-31. [CrossRef]

127. Zhang, S.Y.; Kamal, M.; Dahan, K.; Pawlak, A.; Ory, V.; Desvaux, D.; Audard, V.; Candelier, M.; BenMohamed, F.; Matignon, M.; et al. c-mip impairs podocyte proximal signaling and induces heavy proteinuria. Sci. Signal. 2010, 3, ra39. [CrossRef]

128. Canaud, G.; Bienaimé, F.; Viau, A.; Treins, C.; Baron, W.; Nguyen, C.; Burtin, M.; Berissi, S.; Giannakakis, K.; Muda, A.O.; et al. AKT2 is essential to maintain podocyte viability and function during chronic kidney disease. Nat. Med. 2013, 19, 1288-1296. [CrossRef] [PubMed]

129. Shao, H.; Wu, C.; Wells, A. Phosphorylation of alpha-actinin 4 upon epidermal growth factor exposure regulates its interaction with actin. J. Biol. Chem. 2010, 285, 2591-2600. [CrossRef] [PubMed]

130. Feng, D.; Kumar, M.; Muntel, J.; Gurley, S.B.; Birrane, G.; Stillman, I.E.; Ding, L.; Wang, M.; Ahmed, S.; Schlondorff, J.; et al. Phosphorylation of ACTN4 Leads to Podocyte Vulnerability and Proteinuric Glomerulosclerosis. J. Am. Soc. Nephrol. 2020, 31, 1479-1495. [CrossRef]

131. Bu, X.; Zhou, Y.; Zhang, H.; Qiu, W.; Chen, L.; Cao, H.; Fang, L.; Wen, P.; Tan, R.; Yang, J. Systemic administration of naked plasmid encoding HGF attenuates puromycin aminonucleoside-induced damage of murine glomerular podocytes. Am. J. Physiol. Ren. Physiol. 2011, 301, F784-F792. [CrossRef] [PubMed]

132. Cascone, T.; Xu, L.; Lin, H.Y.; Liu, W.; Tran, H.T.; Liu, Y.; Howells, K.; Haddad, V.; Hanrahan, E.; Nilsson, M.B.; et al. The HGF/c-MET Pathway Is a Driver and Biomarker of VEGFR-inhibitor Resistance and Vascular Remodeling in Non-Small Cell Lung Cancer. Clin. Cancer Res. Off. J. Am. Assoc. Cancer Res. 2017, 23, 5489-5501. [CrossRef] [PubMed]

133. Dienstmann, R.; Brana, I.; Rodon, J.; Tabernero, J. Toxicity as a biomarker of efficacy of molecular targeted therapies: Focus on EGFR and VEGF inhibiting anticancer drugs. Oncologist 2011, 16, 1729-1740. [CrossRef]

134. Shah, D.R.; Shah, R.R.; Morganroth, J. Tyrosine kinase inhibitors: Their on-target toxicities as potential indicators of efficacy. Drug Saf. 2013, 36, 413-426. [CrossRef] [PubMed]

135. de Zeeuw, D.; Agarwal, R.; Amdahl, M.; Audhya, P.; Coyne, D.; Garimella, T.; Parving, H.H.; Pritchett, Y.; Remuzzi, G.; Ritz, E.; et al. Selective vitamin D receptor activation with paricalcitol for reduction of albuminuria in patients with type 2 diabetes (VITAL study): A randomised controlled trial. Lancet 2010, 376, 1543-1551. [CrossRef] 
136. Pollock, C.; Stefánsson, B.; Reyner, D.; Rossing, P.; Sjöström, C.D.; Wheeler, D.C.; Langkilde, A.M.; Heerspink, H.J.L. Albuminurialowering effect of dapagliflozin alone and in combination with saxagliptin and effect of dapagliflozin and saxagliptin on glycaemic control in patients with type 2 diabetes and chronic kidney disease (DELIGHT): A randomised, double-blind, placebo-controlled trial. Lancet. Diabetes Endocrinol. 2019, 7, 429-441. [CrossRef]

137. de Zeeuw, D.; Renfurm, R.W.; Bakris, G.; Rossing, P.; Perkovic, V.; Hou, F.F.; Nangaku, M.; Sharma, K.; Heerspink, H.J.L.; Garcia-Hernandez, A.; et al. Efficacy of a novel inhibitor of vascular adhesion protein-1 in reducing albuminuria in patients with diabetic kidney disease (ALBUM): A randomised, placebo-controlled, phase 2 trial. Lancet. Diabetes Endocrinol. 2018, 6, 925-933. [CrossRef]

138. de Zeeuw, D.; Bekker, P.; Henkel, E.; Hasslacher, C.; Gouni-Berthold, I.; Mehling, H.; Potarca, A.; Tesar, V.; Heerspink, H.J.; Schall, T.J. The effect of CCR2 inhibitor CCX140-B on residual albuminuria in patients with type 2 diabetes and nephropathy: A randomised trial. Lancet. Diabetes Endocrinol. 2015, 3, 687-696. [CrossRef]

139. Schiffer, M.; Teng, B.; Gu, C.; Shchedrina, V.A.; Kasaikina, M.; Pham, V.A.; Hanke, N.; Rong, S.; Gueler, F.; Schroder, P.; et al. Pharmacological targeting of actin-dependent dynamin oligomerization ameliorates chronic kidney disease in diverse animal models. Nat. Med. 2015, 21, 601-609. [CrossRef]

140. Gu, C.; Yaddanapudi, S.; Weins, A.; Osborn, T.; Reiser, J.; Pollak, M.; Hartwig, J.; Sever, S. Direct dynamin-actin interactions regulate the actin cytoskeleton. EMBO J. 2010, 29, 3593-3606. [CrossRef]

141. Soda, K.; Balkin, D.M.; Ferguson, S.M.; Paradise, S.; Milosevic, I.; Giovedi, S.; Volpicelli-Daley, L.; Tian, X.; Wu, Y.; Ma, H.; et al. Role of dynamin, synaptojanin, and endophilin in podocyte foot processes. J. Clin. Investig. 2012, 122, 4401-4411. [CrossRef] [PubMed]

142. Zhong, Y.; Lee, K.; Deng, Y.; Ma, Y.; Chen, Y.; Li, X.; Wei, C.; Yang, S.; Wang, T.; Wong, N.J.; et al. Arctigenin attenuates diabetic kidney disease through the activation of PP2A in podocytes. Nat. Commun. 2019, 10, 4523. [CrossRef] [PubMed] 